Chemical Technology

Division

Chemical Technology

Division

Chemical Technology

Division

Chemical Technology Division

Chemical Technology Division

Chemical Technology

\title{
Hydraulic Performance of a 5-cm Contactor for Caustic-Side Solvent Extraction
}

Division

Chemical Technology

Division

Chemical Technology

Division

Chemical Technology

Division

Chemical Technology

Division

Chemical Technology

Division

Chemical Technology

Division

Chemical Technology

Division

Chemical Technology

Division

Chemical Technology

Division

Chemical Technology

Division

by R. A. Leonard, M. C. Regalbuto, S. B. Aase,

H. A. Arafat, and J. R. Falkenberg

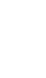


Argonne National Laboratory, with facilities in the states of Illinois and Idaho, is owned by the United States Government and operated by The University of Chicago under the provisions of a contract with the Department of Energy.

\begin{tabular}{l} 
DISCLAIMER \\
This report was prepared as an account of work sponsored by an agency of \\
the United States Government. Neither the United States Government nor \\
any agency thereof, nor The University of Chicago, nor any of their \\
employees or officers, makes any warranty, express or implied, or assumes \\
any legal liability or responsibility for the accuracy, completeness, or \\
usefulness of any information, apparatus, product, or process disclosed, or \\
represents that its use would not infringe privately owned rights. Reference \\
herein to any specific commercial product, process, or service by trade name, \\
trademark, manufacturer, or otherwise, does not necessarily constitute or \\
imply its endorsement, recommendation, or favoring by the United States \\
Government or any agency thereof. The views and opinions of document \\
authors expressed herein do not necessarily state or reflect those of the \\
United States Government or any agency thereof, Argonne National \\
Laboratory, or The University of Chicago. \\
\hline
\end{tabular}

Available electronically at http://www.doe.gov/bridge

Available for a processing fee to U.S. Department of Energy and its contractors, in paper, from:

U.S. Department of Energy

Office of Scientific and Technical Information

P.O. Box 62

Oak Ridge, TN 37831-0062

phone: (865) 576-8401

fax: (865) 576-5728

email: reports@adonis.osti.gov 


\title{
ANL-02/18
}

Argonne National Laboratory Chemical Technology Division 9700 South Cass Avenue Argonne, IL 60439

\section{HYDRAULIC PERFORMANCE OF A 5-CM CONTACTOR FOR CAUSTIC-SIDE SOLVENT EXTRACTION}

\author{
by
}

R. A. Leonard, M. C. Regalbuto, S. B. Aase, H. A. Arafat, and J. R. Falkenberg

December 12, 2001 


\section{CONTENTS}

$\underline{\text { Page }}$

ABSTRACT

I. INTRODUCTION ......................................................................................... 1

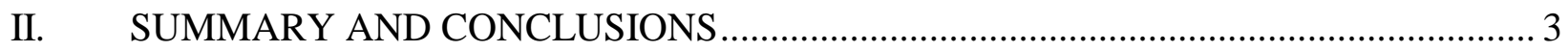

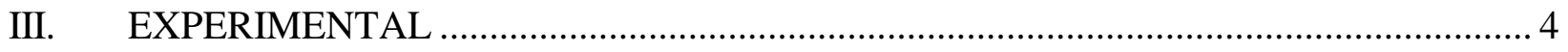

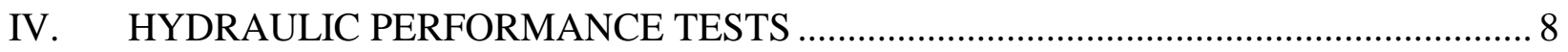

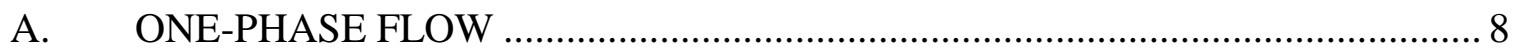

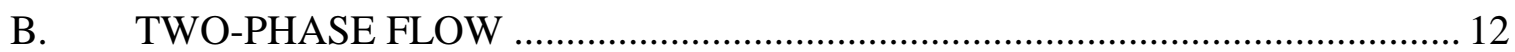

C. LIQUID HEIGHT IN MIXING ZONE …………........................................ 15

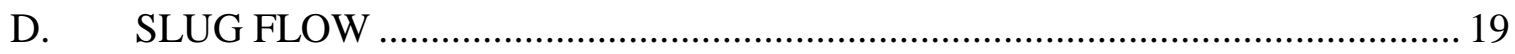

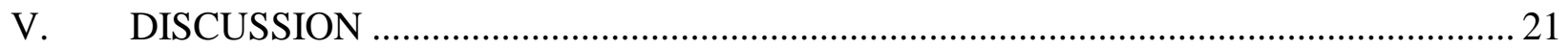

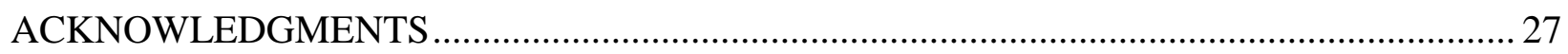

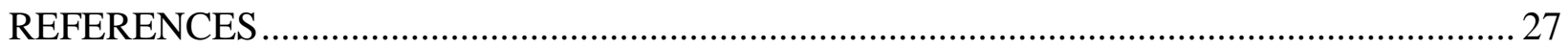




\section{FIGURES}

No.

$\underline{\text { Page }}$

1. Operating 5-cm CINC Contactor at $2.4 \mathrm{~L} / \mathrm{min}$ at an O/A Flow Ratio of 0.3

Using the Four-Component Feed and the CSSX Solvent ........................................... 6

2. Schematic for Annular Centrifugal Contactor..................................................... 7

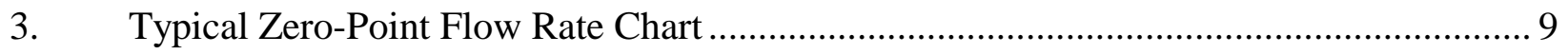

4. Comparison of Actual Upper-Weir Diameter for the 5-cm CINC Contactor with Various Radius Values

5. Maximum Throughput for 5-cm CINC Contactor under CSSX Extraction Section Conditions

6. Maximum Throughput for 5-cm CINC Contactor under CSSX Strip Section Conditions 14

7. Annular Liquid Height in 5-cm CINC Contactor Using Four Straight Bottom Vanes and Water ....

8. Annular Liquid Height in 5-cm CINC Contactor Using Eight Straight Bottom Vanes and Water ...

9. Annular Liquid Height in 5-cm CINC Contactor Using Eight Curved Bottom Vanes and Water...

10. Annular Liquid Height in 5-cm CINC Contactor Using Eight Straight Bottom Vanes and CSSX Conditions

\section{TABLES}

No.

1. Zero-Point Flow Rates for 5-cm CINC Contactor ...................................................... 10

2. Apparent Radius of Upper Weir for 5-cm CINC Contactor....................................... 11

3. Apparent Radius of Upper Weir for Several Contactors Based on One-Phase Flow Tests 


\section{TABLES (continued)}

No.

$\underline{\text { Page }}$

4. Apparent Radius of Upper Weir for Several Contactors Based on Two-Phase

Flow Tests

5. Slug Volume as Flowing Water Exits from 5-cm CINC Contactor... 


\title{
HYDRAULIC PERFORMANCE OF A 5-CM CONTACTOR FOR CAUSTIC-SIDE SOLVENT EXTRACTION
}

by

\author{
R. A. Leonard, M. C. Regalbuto, S. B. Aase, H. A. Arafat, and J. R. Falkenberg
}

\begin{abstract}
The hydraulic performance of a 5-cm centrifugal contactor from Costner Industries Nevada Corporation (CINC) was measured for both one- and two-phase flow. Flow conditions and test liquids as well as the liquid height in the annular mixing zone and the occurrence of discontinuous (slug) flow in the interstage lines are reported. Results are compared with earlier results obtained using 2- and 4-cm contactors made at Argonne National Laboratory. In each case, one-phase flow tests can be used to predict behavior in two-phase flow. This makes the one-phase flow test a quality control tool for evaluating contactor rotors as they are manufactured. These results indicate that the $5-\mathrm{cm}$ contactor works in the same way as the 2and 4-cm contactors.
\end{abstract}

\section{INTRODUCTION}

Because of its high stage efficiency and its high throughput per unit volume, the centrifugal contactor is the equipment of choice for solvent extraction processes where solvent cost is high. The centrifugal contactor will be used to carry out the caustic-side solvent extraction (CSSX) process for cesium removal from high-level waste at the Savannah River Site (SRS). It is one step of an overall decontamination process that will be applied to the 34 million gallons (129 million L) of high-level waste at SRS [LEVENSON-2000]. After the cesium is removed from the SRS waste and concentrated by the CSSX process, the cesium will be combined with sludge and vitrified for disposal. The decontaminated waste solution will be immobilized in low-level grout.

Work performed at Argonne National Laboratory (ANL) in FY2000 and FY2001 has shown that cesium can be extracted from caustic aqueous solutions representative of the high-level waste at SRS using solvent extraction carried out in 2-cm centrifugal contactors [R. LEONARD-2000, -2001A]. In these proof-of-concept tests, the CSSX process achieved both key process goals: (1) the cesium was removed from the waste with decontamination factors 
greater than 40,000 and (2) the recovered cesium was concentrated by a factor of 15 in dilute nitric acid. In the final test, the solvent was recycled 42 times while the process was run around the clock for three days. In addition, a CSSX flowsheet test was run with actual waste at the Savannah River Technical Center (SRTC). This two-day test also achieved both key goals [CAMPBELL-2001]. Based on the success of these tests, solvent extraction was chosen as the preferred technology to use in the SRS waste facility for the removal of cesium [U.S. DEPARTMENT OF ENERGY-2001].

Our objective was to test a model for the design of annular centrifugal contactors. This model would be used to guide the design of contactors for pilot- and plant-scale operations. The model was tested by comparing its predictions with the actual hydraulic performance of a 5-cm centrifugal contactor from Costner Industries Nevada Corporation (CINC, Carson City, Nevada). The original centrifugal contactor for carrying out countercurrent stagewise solvent extraction operations was designed by SRS with a turbine mixer below the rotor [WEBSTER-1969]. The SRS design was simplified at ANL in the early 1970s [BERNSTEIN-1973]. The turbine mixer was eliminated and the annular region around the outer wall of the spinning rotor was enlarged and used as the new mixing zone. Centrifugal contactors with an annular mixing zone are often referred to as "ANL centrifugal contactors" or "annular centrifugal contactors." As with most of the contactors built since the 1970s, the CINC contactors have an annular mixing zone.

The work reported here builds on earlier work that evaluated the hydraulic performance of the 5-cm CINC contactor for a variety of rotor speeds as well as stage efficiency [BIRDWELL-2001A]. In that work, the maximum throughput (both phases) for the extraction section was found to be $634 \mathrm{~mL} / \mathrm{min}$, much less than the nominal $2000 \mathrm{~mL} / \mathrm{min}$ rating given by the manufacturer. The difference may be due to (1) the use of an older CINC rotor, (2) the rotor modification, i.e., opening up the rotor inlet, (3) a different two-phase system being used in the testing, or (4) some other unidentified cause. In the work reported here, we tested the latest CINC rotor and did not open the rotor inlet. The CINC housing was acrylic with tangential ports into the mixing zone. Its bottom vanes could be either straight or curved. Using just one rotor speed $(3600 \mathrm{rpm})$, we found the maximum throughput of the CINC unit for the key sections (extraction and strip) of the CSSX process. The 5-cm CINC contactor results are compared with earlier results using 2- and 4-cm contactors that have been used extensively at ANL. After completing the work reported here, we learned that Birdwell has achieved good hydraulic performance at $1310 \mathrm{~mL} / \mathrm{min}$ for extraction section conditions with an unmodified rotor [BIRDWELL-2001B]. As testing was limited by the pump capacity, the maximum flow rate is greater than $1310 \mathrm{~mL} / \mathrm{min}$. 


\section{SUMMARY AND CONCLUSIONS}

The centrifugal contactor model works well for the 5-cm contactor designed and built at CINC as well as for the 2- and 4-cm contactors designed and built at ANL. From this work, as well as earlier work with larger contactors (up to $25 \mathrm{~cm}$ ), the model appears to be a reasonable basis for designing and evaluating a contactor for pilot-plant and full-scale facilities.

One- and two-phase flow tests have about the same apparent radius for the upper weir of a given rotor. As a result, either test can be used to evaluate a new rotor design or to check the quality of an existing rotor. Because the one-phase flow test is quick, it is an easy way to evaluate the quality of a rotor.

Flow fluctuations, which could reduce stage efficiency in multistage operations, should not be a problem for a $1 / 100$-scale pilot plant for the CSSX process where interstage flow rates would be $25 \mathrm{~mL} / \mathrm{min}$ and higher. While some flow fluctuations were observed from 25 to $50 \mathrm{~mL} / \mathrm{min}$, their volume was small compared with the liquid volume in the annular mixing zone. As a result, they should reduce stage efficiency for a multistage operation only slightly, possibly from 90 to $85 \%$, but that is still higher than the stage efficiency of $80 \%$ that was the design basis for the CSSX process.

Flow fluctuations can also occur when the liquid in the annular mixing zone loses contact with the rotor, which occurred in the 5-cm CINC contactor at total flow rates from 30 to $70 \mathrm{~mL} / \mathrm{min}$. The resulting fluctuations are large and could cause stage efficiency to drop below $60 \%$, so they should be avoided. Operations at higher flow rates did not show this problem. Since the minimum flow rate for a 1/100-scale pilot plant would be $150 \mathrm{~mL} / \mathrm{min}$ (both phases), this type of flow fluctuation would not occur if the 5-cm CINC contactor were used.

Based on this work, the 5-cm CINC contactor is a potential candidate for a 1/100-scale pilot plant for the CSSX process. However, before it is selected, several concerns need to be addressed: (1) The contactor needs to be tested with the new CSSX solvent, which will have a higher solvent density. (2) Stage efficiency needs to be checked for single-stage and multistage operation at the required process flow rates. (3) Liquid height in the annular mixing zone should be rechecked with the new CSSX solvent. (4) Hydraulic performance needs to be tested for multistage operation with interstage lines of an appropriate shape. 


\section{EXPERIMENTAL}

The CSSX solvent used in these tests was the baseline solvent for FY2000 and FY2001 tests. This solvent composition was developed at Oak Ridge National Laboratory (ORNL) in FY1999 [BONNESEN-2000]. It has four components: (1) an extractant-a calixarene crown, calix[4]arene-bis(tert-octylbenzo-crown-6) designated BOBCalixC6, or Calix; (2) a modifieran alkyl aryl polyether, 1-(2,2,3,3,-tetrafluoropropoxy)-3-(4-sec-butylphenoxy)-2-propanol, also called Cs-7SB; (3) a suppressant-an alkyl amine, trioctylamine (TOA), which suppresses impurity effects to ensure that the cesium can be stripped from the solvent; and (4) a diluent-a mixture of branched hydrocarbons, Isopar ${ }^{\circledR} \mathrm{L}$. The composition of the baseline CSSX solvent is $0.01 \underline{\mathrm{M}}$ BOBCalixC6, $0.50 \underline{\mathrm{M}} \mathrm{Cs}-7 \mathrm{SB}$, and $0.001 \underline{\mathrm{M}}$ TOA in Isopar ${ }^{\circledR} \mathrm{L}$. This solvent was prepared and supplied by P. V. Bonnesen at ORNL. As prepared, it had a density of $822.7 \pm 0.2$ $\mathrm{g} / \mathrm{L}$ at $25^{\circ} \mathrm{C}$ [MOYER-2001]. Before the solvent was used in the 5-cm CINC hydraulic tests, it had been used for decanter tests in a 4-cm contactor. At the start of the 5-cm tests, the solvent had an estimated density of $836 \mathrm{~g} / \mathrm{L}$ at $25^{\circ} \mathrm{C}$, based on our experience with the solvent recovery tests in a 4-cm contactor, which were similar to the decanter tests. At the end of the 5-cm tests, the solvent had a density of $848 \mathrm{~g} / \mathrm{L}$ at $25^{\circ} \mathrm{C}$. To model the two-phase hydraulic tests, an average density of $842 \mathrm{~g} / \mathrm{L}$ at $25^{\circ} \mathrm{C}$ was used for the CSSX solvent. Note that slight modifications to the proportions of the CSSX solvent constituents are expected in FY2002. Additional testing may be required to verify that these changes do not affect the hydraulic performance of the CSSX process.

Various aqueous phases were used for the tests. The one-phase flow tests used water. The aqueous phase for the two-phase flow tests was $0.001 \underline{\mathrm{M}} \mathrm{HNO}_{3}$ for the strip section. For the extraction section, the aqueous phase consisted of the four most abundant components of the SRS waste simulant as given by [PETERSON 2000]. Using a density correlation based on the concentration of $\mathrm{Na}^{+}$, the SRS simulant has an estimated density of $1258 \mathrm{~g} / \mathrm{L}$ at $22^{\circ} \mathrm{C}$ [WALKER-1998]. The composition of this four-component feed was $2.06 \underline{\mathrm{M}} \mathrm{NaOH}, 2.03 \underline{\mathrm{M}}$ $\mathrm{NaNO}_{3}, 0.50 \underline{\mathrm{M}} \mathrm{NaNO}_{2}$, and $0.28 \underline{\mathrm{M}} \mathrm{Al}\left(\mathrm{NO}_{3}\right)_{3}$. Using the same density correlation, the fourcomponent feed has an estimated density of $1213 \mathrm{~g} / \mathrm{L}$ at $22^{\circ} \mathrm{C}$. Its measured density is $1214 \mathrm{~g} / \mathrm{L}$ at $25^{\circ} \mathrm{C}$. In the four-component simulant, $\mathrm{NaOH}$ reacts with $\mathrm{Al}\left(\mathrm{NO}_{3}\right)_{3}$ as follows:

$$
\mathrm{Al}\left(\mathrm{NO}_{3}\right)_{3}+4 \mathrm{NaOH} \rightarrow \mathrm{NaAlO}_{2}+3 \mathrm{NaNO}_{3}+2 \mathrm{H}_{2} \mathrm{O} .
$$

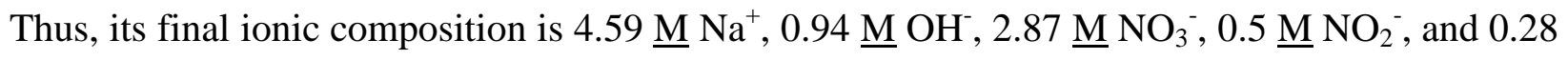
$\underline{\mathrm{M}} \mathrm{AlO}_{2}{ }^{-}$. The organic-to-aqueous (O/A) flow ratio was 0.33 in the extraction section, and 5.0 in the strip section. 
The tests reported here used a single-stage 5-cm CINC contactor. This unit, shown in Figure 1, is also called a V-2 centrifugal extractor by CINC and is listed as item number U-17315-04 in the 2001/02 Cole-Parmer catalog. Note that the contactor size refers to the diameter of the rotor. The 5-cm CINC contactor has a standard motor and operates at $110 \mathrm{~V} \mathrm{AC}$. The actual rotor speed was found to be $4 \%$ less than that shown on the speed controller. We calibrated the speed controller using a strobe-light tachometer so that all tests were conducted at $3600 \mathrm{rpm}$. Although the 5-cm CINC contactor comes with a stainless steel housing having perpendicular inlet ports, we ordered an acrylic housing from CINC so that we could see the liquid height. This housing had tangential inlet ports. In addition, we ordered two polyvinylidene fluoride (PVDF) housing bottoms with eight straight vanes to replace the bottom plate containing eight curved stainless steel vanes that came with the CINC unit. One of the 5-cm CINC units at ORNL was modified and tested with eight straight vanes by ORNL [BIRDWELL-2001A]. The eight-straight-vane design is used in the 2- and 4-cm contactors. On one of the PVDF housing bottoms, we machined off every other vane to make a four-straightvane bottom plate. The results for the 5-cm CINC contactor with the eight-straight-vane bottom plate are compared with results for 2- and 4-cm ANL contactors, which both operate at $3600 \mathrm{rpm}$. Information on the 2-cm contactor is given in R. LEONARD-1997, -2001B, and -2001C. Information on the 4-cm contactor is given in R. LEONARD-1983, -1988, and -1993. 


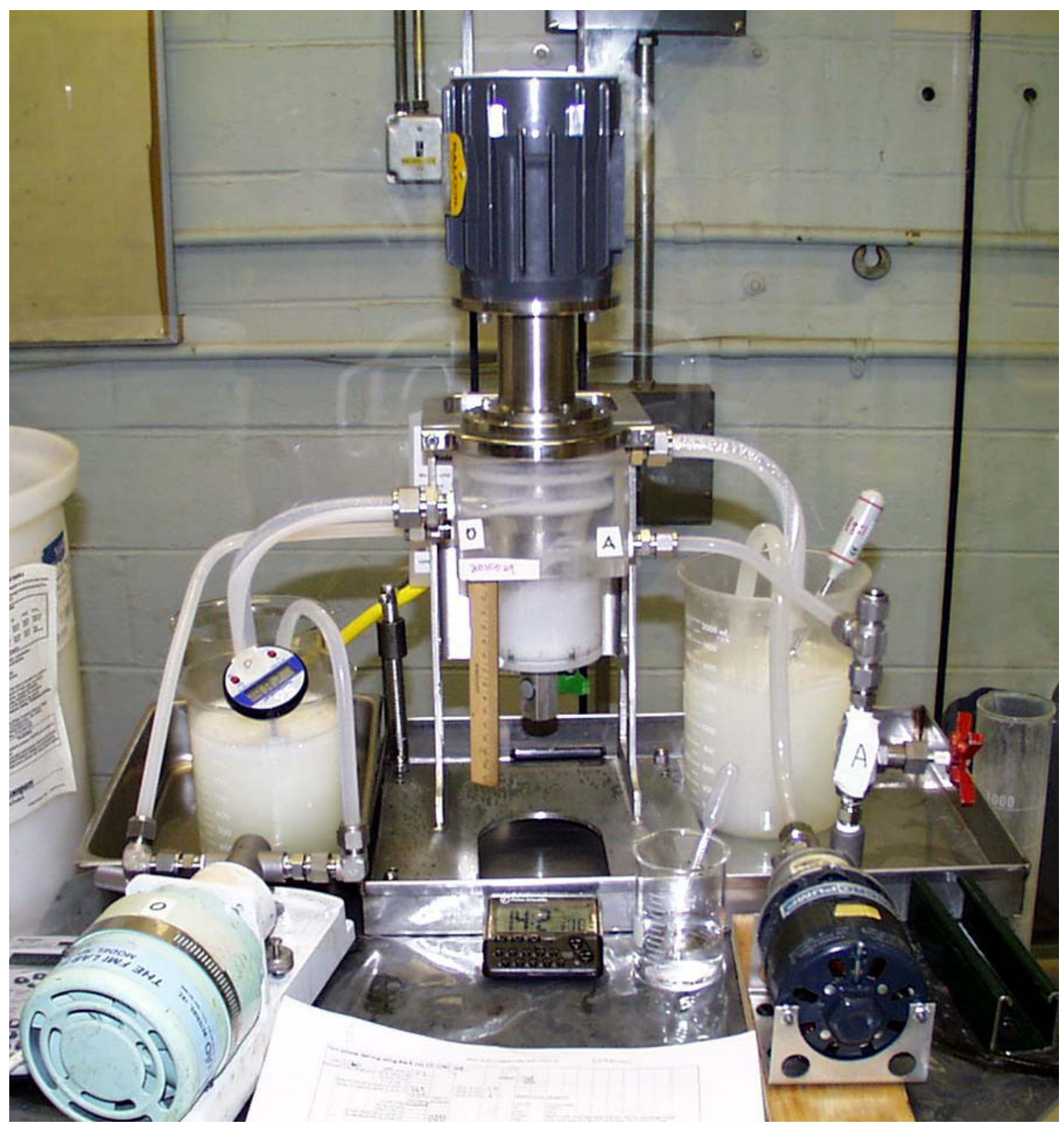

Fig. 1. Operating 5-cm CINC Contactor at $2.4 \mathrm{~L} / \mathrm{min}$ (both phases) at an O/A Flow Ratio of 0.3 Using the Four-Component Feed and the CSSX Solvent

The basic design for the annular centrifugal contactor is shown schematically in Figure 2. The two immiscible liquids flow by gravity from stage to stage to the housing inlets. They enter each stage through the inlet ports into the annular mixing zone around the rotor. In the CSSX process, the less-dense phase is the organic phase; the more-dense phase is the aqueous phase. The upper weir is for the more-dense phase; the lower weir is for the less-dense phase. The dispersion created as these two phases enter the annular mixing zone flows down to the bottom and enters the rotor through an inlet in the bottom. While the residence time in the mixing zone is short, typically a few seconds, the mass transfer efficiency is high, usually greater than $95 \%$. Once inside the rotor, the high centrifugal forces quickly separate the dispersion into two phases and, using baffles and weirs, the two phases exit separately. They are slung into their respective collector rings where, typically, the momentum of each liquid phase carries it out the appropriate 
tangential exit port. From there, the two phases continue their countercurrent flow to the adjacent stages.

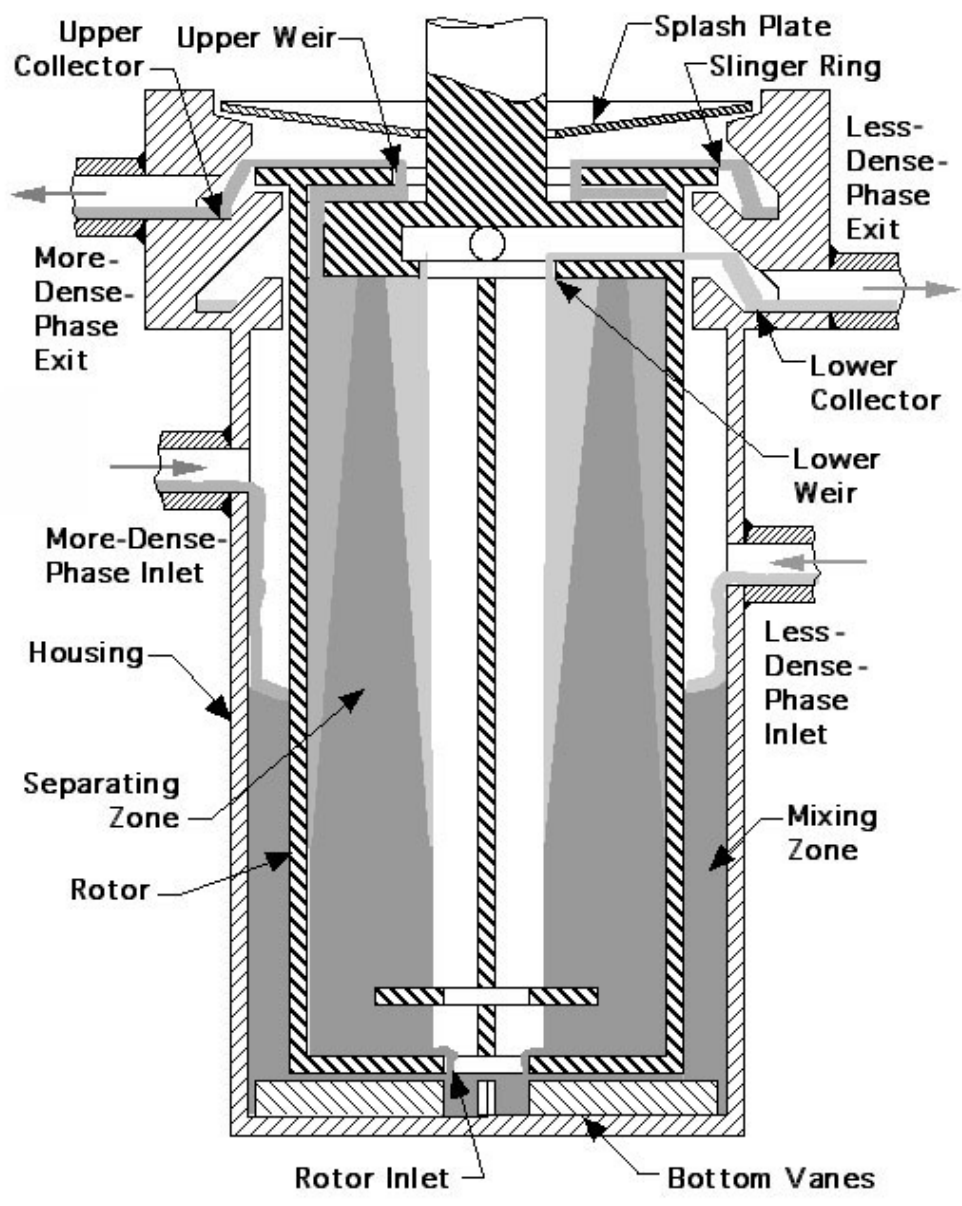

Fig. 2. Schematic for Annular Centrifugal Contactor

The annular contactor design has many advantages based on four key features. First, it is a system with low liquid volume. As a result, contactors have short residence times, rapid response to process changes, small footprint, and low solvent inventory, and they reach steady state quickly. Low solvent inventory is especially important when the solvent is expensive, as it is for the CSSX solvent. Second, the contactor has high stage efficiency. This means that process scale-up is easy since the same number of stages can be used. Third, the motor/rotor assembly can be easily removed. This provides ease of maintenance, which is especially important when the contactor is used remotely. Fourth, a bank of contactor stages can be stopped at any time and later restarted at essentially unchanged process conditions, for example, at steady state. Thus, many process problems can be fixed without the loss of steady-state operating conditions. 


\section{HYDRAULIC PERFORMANCE TESTS}

Hydraulic performance testing involved one- and two-phase flow tests. The one-phase flow test results were evaluated using a model that takes into account the height of the liquid over each weir based on flow rate and liquid density [DAVIS-1961]. The two-phase flow test results were evaluated using the same model combined with the thickness of the dispersion band in the rotor as given by the dispersion number [R. LEONARD-1981]. To allow the establishment of steady-state conditions, the flows were maintained for at least three residence times before samples were taken. Both models give an apparent radius for the more-dense-phase weir $\left(r_{m d, ~ a p p}\right)$ that can be compared with the measured radius for the more-dense-phase weir $\left(\mathrm{r}_{\mathrm{md}}\right.$ act $)$. As these tests were being completed, the liquid flow in the exit lines was noted along with the liquid height in the annular mixing zone. After the one- and two-phase tests were completed, further testing was done to characterize the liquid flow in exit lines and the liquid height in the annular mixing zone. These tests are important as they validate the hydraulic model that would be used to guide the design of contactors for pilot-plant and full-scale operations.

\section{A. One-Phase Flow}

One-phase flow tests are used to determine the zero-point flow rate for the rotor. The zero-point flow rate is defined as the point where, as the flow rate is increased, liquid starts to come out the less-dense-phase exit. In the one-phase tests, measurements are made both above and below the zero-point flow rate. The data, plotted in Figure 3, are for a 5-cm CINC contactor with an upper-weir diameter of $0.875 \mathrm{in} .(22.2 \mathrm{~mm})$. The data are interpolated to determine the zero-point flow rate. Then the one-phase flow model is used to calculate the apparent radius for the more-dense-phase weir based on this zero-point flow rate. Finally, the apparent radius is compared with the actual radius. 


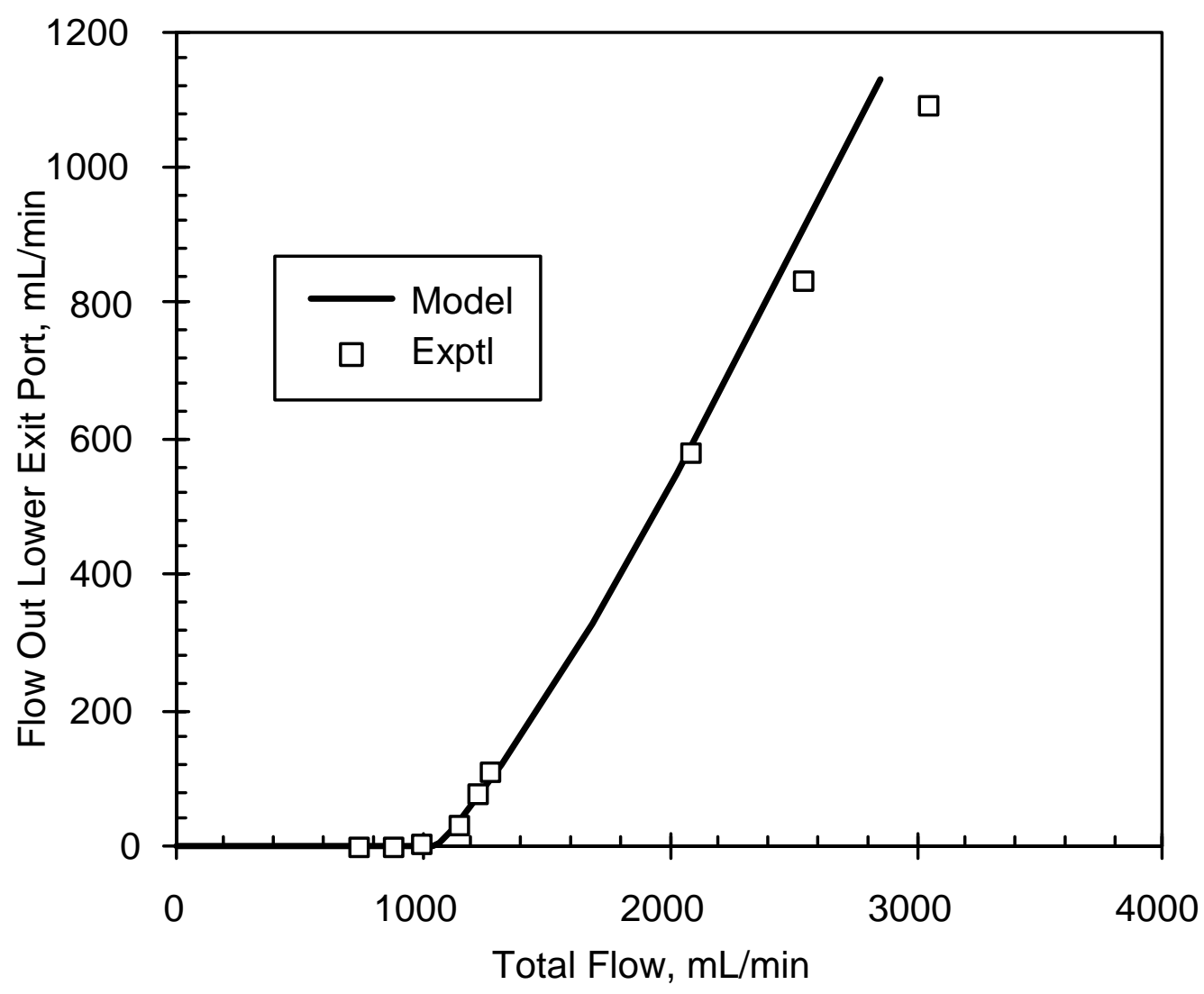

Fig. 3. Typical Zero-Point Flow Rate Chart

The 5-cm CINC contactor comes with a set of ten interchangeable upper weirs having weir diameters that range from 0.825 to $1.050 \mathrm{in}$. (21.0 to $26.7 \mathrm{~mm}$ ). (The diameter increases in increments of 0.025 in. [0.64 mm].) We developed a plan for the selective testing of these weirs. Our plan was to start zero-point testing with the smaller weirs, continuing up until the zero-point flow rate exceeded the stated $2000 \mathrm{~mL} / \mathrm{min}$ capacity of the unit. The diameter of the lower weir, $0.816 \mathrm{in} .(20.7 \mathrm{~mm})$, was the same in all cases and is not interchangeable. We started with one of the smaller upper weirs, as they work well for a wide range of density differences between the two phases. However, when the radii of the upper and lower weirs are close together, high throughputs that are near the maximum predicted by the dispersion number [R. LEONARD-1981] are possible only when the densities of the two phases are close together. At the maximum throughput for a given O/A flow ratio, the optimum upper-weir radius is the one where a further increase in throughput will result in both $>1 \%$ aqueous phase in the organic effluent ( $\mathrm{A}$ in $\mathrm{O}$ ) and $>1 \%$ organic phase in the aqueous effluent $(\mathrm{O}$ in $\mathrm{A})$. As the density differences between the two phases become greater, larger upper-weir diameters are needed to get close to the maximum throughput. For our zero-point tests, we started with an upper-weir diameter of $0.850 \mathrm{in} .(21.6 \mathrm{~mm})$. After the test was completed, the weir diameter was increased 
and the test was repeated. We stopped with an upper-weir diameter of $0.950 \mathrm{in}$. $(24.1 \mathrm{~mm})$ since its zero-point flow rate was well above $2000 \mathrm{~mL} / \mathrm{min}$. Zero-point flow rates are given for each test in Table 1.

Table 1. Zero-Point Flow Rates for 5-cm CINC Contactor

\begin{tabular}{|c|c|c|c|}
\hline $\begin{array}{c}\text { Actual Upper-Weir } \\
\text { Diameter, in. (mm) }\end{array}$ & $\begin{array}{c}\text { Zero-Point Flow } \\
\text { Rate, mL/min }\end{array}$ & $\begin{array}{c}\text { No-Flow Mixing- } \\
\text { Zone Volume } \mathbf{~} \mathbf{m L}\end{array}$ & $\begin{array}{c}\text { No-Flow Rotor } \\
\text { Volume } \mathbf{~ m L}\end{array}$ \\
\hline $0.850(21.6)$ & 467 & 1.2 & 162 \\
\hline $0.875(22.2)$ & 1041 & 6.0 & 160 \\
\hline $0.875^{\mathrm{c}}(22.2)$ & 1057 & 1.9 & 158 \\
\hline $0.900(22.9)$ & 1592 & 1.1 & 159 \\
\hline $0.925(23.5)$ & 2753 & 2.5 & 156 \\
\hline $0.950(24.1)$ & 3318 & 2.5 & 152 \\
\hline
\end{tabular}

${ }^{a}$ At no-flow conditions. The rotor is still spinning.

${ }^{\mathrm{b}}$ At no-flow conditions after the annular region is drained. The rotor is not spinning.

${ }^{\mathrm{c}}$ Repeat of earlier 0.875 -in. $(22.2-\mathrm{mm})$ weir test because volume outside rotor seemed high.

After each zero-point test was completed, the liquid flow was stopped, but the rotor was allowed to continue spinning. After as much liquid as possible was pumped out of the contactor stage, the liquid in the annular mixing zone was drained from the rotor and its volume measured. This was done by opening the bottom drain while keeping the rotor spinning. When the rotor was turned off, the liquid inside the rotor was released. This liquid volume was also collected and measured. The liquid volumes are listed in Table 1 . Note that the residual volume in the annular mixing zone was quite low, ranging from 1.1 to $6.0 \mathrm{~mL}$. This volume is independent of the upper-weir diameter. The no-flow volume inside the rotor ranged from 152 to $162 \mathrm{~mL}$. As expected, this volume decreased as the diameter of the upper weir increased.

Using the one-phase flow model, the apparent radius for the upper weir was determined from the zero-point flow rates given in Table 1. The results, given in Table 2 and Figure 4, show that the apparent radius is greater than the actual radius for all weirs tested. The apparent upperweir radii for the first three weirs tested are slightly higher than the actual radii. A least-squares fit of these data points gives

$$
r_{m d, a p p}=a_{0}+a_{1} \bullet d_{m d, a c t},
$$

where $a_{0}$ is $-3.57 \mathrm{~mm}, a_{1}$ is $16.99 \mathrm{~mm} / \mathrm{in} ., d_{m d}$, act is the actual diameter of the upper weir in inches, and $r_{m d, \text { app }}$ is the apparent radius of the upper weir in $\mathrm{mm}$. This equation is the dashed line in Figure 4. Note that the last two values for the apparent upper-weir radius are well above 
the dashed line. The zero-point flow rates for these two weirs are well above the $2000 \mathrm{~mL} / \mathrm{min}$ rated capacity for this contactor. Such high flow rates apparently give rise to effects that are not important at lower flow rates-that is, as long as the contactor is operated within its nominal flow range of 50 to $2000 \mathrm{~mL} / \mathrm{min}$. As long as more-dense-phase flow rates are no higher than $2 \mathrm{~L} / \mathrm{min}$, the apparent radius for these two upper weirs (as well as for any larger upper weirs) should be the corrected apparent upper-weir radius given by Equation 2.

Table 2. Apparent Radius of Upper Weir for 5-cm CINC Contactor

\begin{tabular}{|c|c|c|c|}
\hline $\begin{array}{c}\text { Actual Upper- } \\
\text { Weir Diameter, in. } \\
(\mathbf{m m})\end{array}$ & $\begin{array}{c}\text { Actual Upper- } \\
\text { Weir Radius, } \\
\text { mm }\end{array}$ & $\begin{array}{c}\text { Apparent Upper- } \\
\text { Weir Radius, mm }\end{array}$ & $\begin{array}{c}\text { Corrected Apparent } \\
\text { Upper-Weir Radius, mm }\end{array}$ \\
\hline $0.850(21.6)$ & 10.80 & 10.87 & 10.87 \\
\hline $0.875(22.2)$ & 11.11 & 11.29 & 11.30 \\
\hline $0.875^{\mathrm{a}}(22.2)$ & 11.11 & 11.30 & 11.30 \\
\hline $0.900(22.9)$ & 11.43 & 11.72 & 11.72 \\
\hline $0.925^{\mathrm{b}}(23.5)$ & 11.75 & 12.76 & 12.15 \\
\hline $0.950^{\mathrm{b}}(24.1)$ & 12.07 & 13.34 & 12.57 \\
\hline
\end{tabular}

${ }^{\mathrm{a}}$ Repeat of earlier 0.875 -in. $(22.2 \mathrm{~mm})$ weir test because volume outside rotor seemed high.

bid not use this value for the "apparent upper-weir radius" in developing the correlation for the "corrected apparent upper-weir radius" as its zero-point flow rate is above the rated capacity of the contactor.

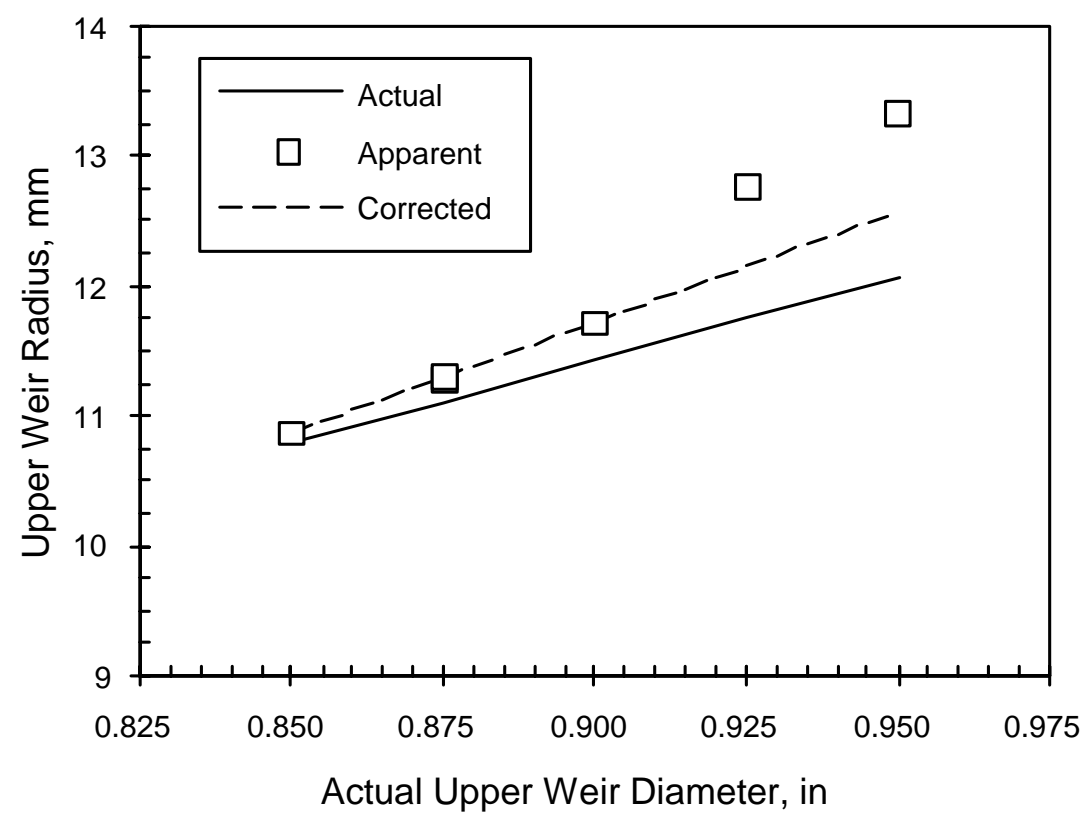

Fig. 4. Comparison of Actual Upper-Weir Diameter for the 5-cm CINC Contactor with Various Radius Values 
Using the apparent radius, the 5-cm CINC contactor is compared with the 2- and 4-cm contactors. The results, which are listed in Table 3, show the average value of the apparent upper-weir radius relative to the actual upper-weir radius. The $2-\mathrm{cm}$ data are from $[\mathrm{R}$. LEONARD 2001B]; the 4-cm data are from [ARAFAT 2002]. Note that, for both ANL-built contactors, the apparent upper-weir radii are 0.6 to $4.0 \%$ less than the actual upper-weir radii. This result is just the opposite of that for the 5-cm CINC contactor. For the CINC unit, the apparent upper-weir radius is $4.1 \%$ more than the actual upper-weir radius. We then conducted the two-phase flow tests to see if this pattern is repeated there.

Table 3. Apparent Radius of Upper Weir for Several Contactors Based on One-Phase Flow Tests

\begin{tabular}{|c|c|c|c|c|c|}
\hline $\begin{array}{c}\text { Contactor } \\
\text { Size, cm }\end{array}$ & $\begin{array}{c}\text { Number of } \\
\text { Rotors Tested }\end{array}$ & $\begin{array}{c}\text { Actual } \\
\text { Upper-Weir } \\
\text { Radius, mm }\end{array}$ & $\begin{array}{c}\text { Apparent Upper- } \\
\text { Weir Radius, mm }\end{array}$ & $\Delta \mathbf{r} / \mathbf{r}, \%^{\mathbf{a}}$ & Notes \\
\hline 2 & 36 & 6.12 & 5.95 & -2.8 & $\mathrm{~b}$ \\
\hline & 40 & 6.24 & 6.15 & -1.4 & $\mathrm{c}$ \\
\hline & 4 & 6.12 & 5.97 & -2.5 & $\mathrm{~d}$ \\
\hline & 4 & 6.24 & 6.20 & -0.6 & $\mathrm{e}$ \\
\hline & 37 & 6.24 & 6.15 & -1.4 & $\mathrm{f}$ \\
\hline 5 & 4 & 8.80 & 8.45 & -4.0 & $\mathrm{~g}$ \\
\hline 5 & 1 & 12.07 & 12.57 & 4.1 & $\mathrm{~h}$ \\
\hline
\end{tabular}

${ }^{\mathrm{a}} \Delta \mathrm{r} / \mathrm{r}=[$ (apparent upper-weir radius) - (actual upper-weir radius) $]$ / (actual upper-weir radius).

${ }^{\mathrm{b}}$ Rotors were tested as built.

${ }^{c}$ After these rotors were built with an upper-weir radius of $6.12 \mathrm{~mm}$, the upper-weir opening was enlarged using electrical discharge machining (EDM).

${ }^{\mathrm{d}}$ These four rotors were tested as built.

${ }^{\mathrm{e}}$ The same four rotors after upper-weir opening was enlarged using EDM.

${ }^{\mathrm{f}}$ All of these rotors had initially been built with an upper-weir radius of $6.12 \mathrm{~mm}$. The zero-point test results summarized here were done after their upper-weir opening had been enlarged using EDM.

${ }^{\mathrm{g}}$ Rotors of the latest design.

${ }^{\mathrm{h}}$ CINC rotor with 0.950 -in. (24.1-mm) upper weir. Value for the apparent upper-weir radius has been corrected as described in text and given in Table 2.

\section{B. Two-Phase Flow}

Two-phase flow tests are done to experimentally determine the maximum flow rate for a pair of immiscible liquids at the desired O/A flow ratio. The maximum flow rate is determined by increasing the flow rate at a given $\mathrm{O} / \mathrm{A}$ flow ratio until one sees $>1 \% \mathrm{~A}$ in $\mathrm{O}$ or $>1 \% \mathrm{O}$ in $\mathrm{A}$. In the two-phase tests, measurements are typically made both above and below the maximum flow rate and the data are interpolated to get the actual maximum flow rate. Then the two-phase 
flow model is used to calculate the apparent radius for the more-dense-phase weir based on this flow rate and the mode of failure, either $\mathrm{A}$ in $\mathrm{O}$ or $\mathrm{O}$ in $\mathrm{A}$.

Based on the results for the one-phase flow tests, we decided to use the 5-cm CINC contactor with an upper-weir diameter of $0.950 \mathrm{in} .(24.1 \mathrm{~mm})$. This diameter represents a compromise between the extraction and strip section needs. It gives a fairly good extraction-section operation and works well for the strip section or when flushing the extraction section with water. Tests were done under extraction conditions for the CSSX process at an O/A flow ratio of 0.33 and under strip conditions at an O/A of 5.0. The two-phase flow model uses a dimensionless dispersion number of $8 \times 10^{-4}$. This is an average value based on dispersion numbers around $4 \times 10^{-4}$ for vial tests and $12 \times 10^{-4}$ for cylinder tests [MOYER-2001]. The model-generated chart for analyzing the extraction-section test is given in Figure 5. The model-generated chart for analyzing the strip-section test is given in Figure 6. The results, given in Table 4, show that the apparent radius for the upper weir is greater than the actual radius. The amount of this change, 2.3 to $5.7 \%$, is in the same range as that for the one-phase flow tests.

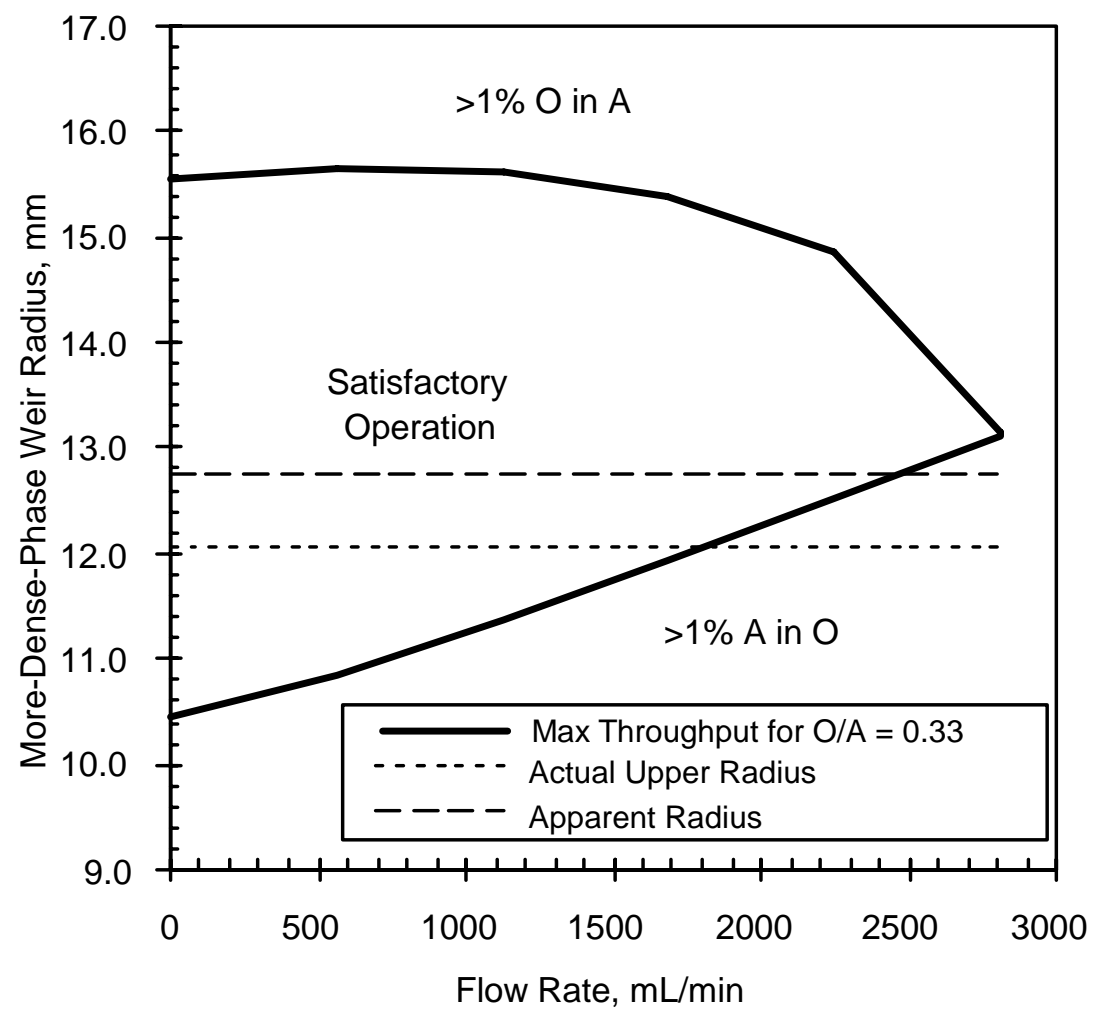

Fig. 5. Maximum Throughput for 5-cm CINC Contactor under CSSX Extraction Section Conditions 


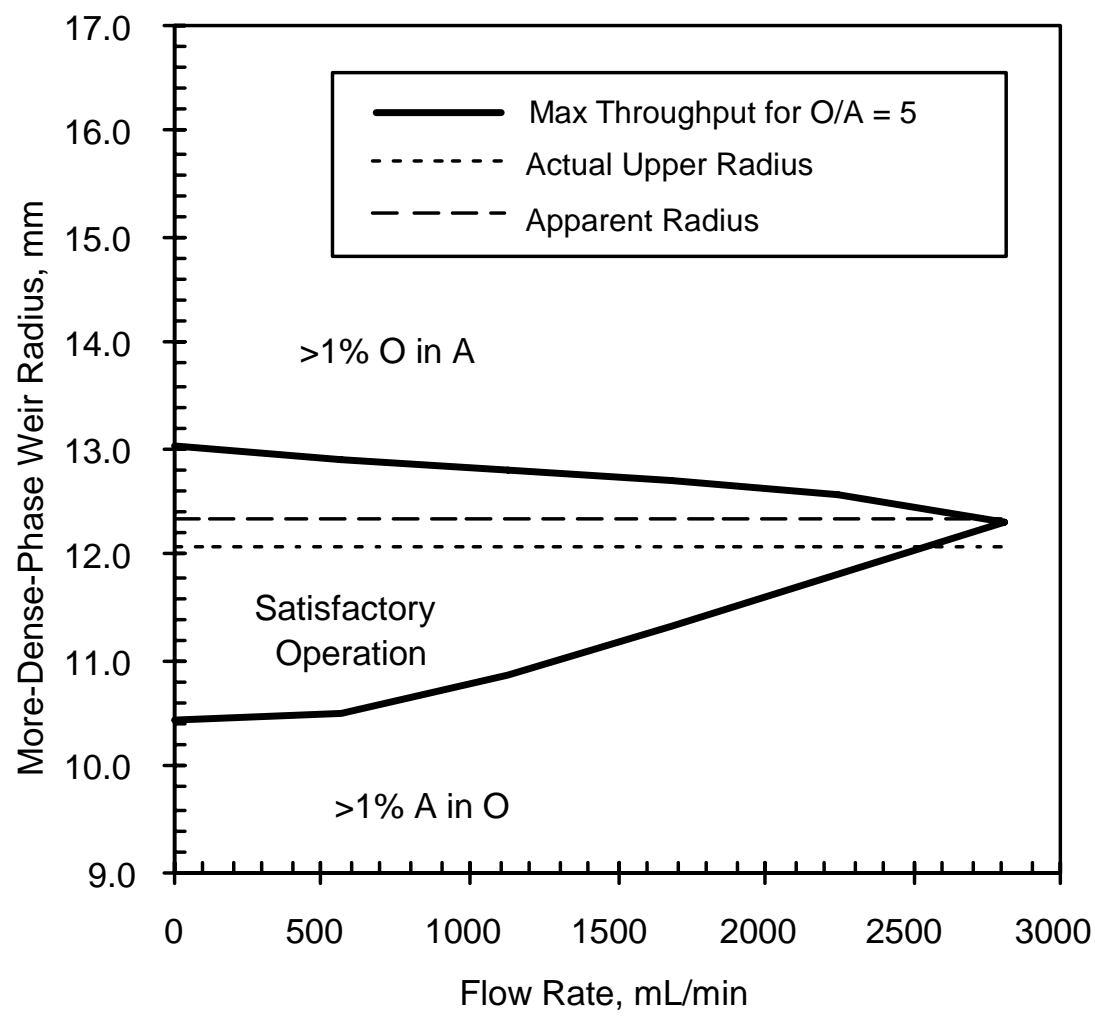

Fig. 6. Maximum Throughput for 5-cm CINC Contactor under CSSX Strip Section Conditions 
Table 4. Apparent Radius of Upper Weir for Several Contactors

Based on Two-Phase Flow Tests

\begin{tabular}{|c|c|c|c|c|c|c|c|c|}
\hline $\begin{array}{c}\text { Contactor } \\
\text { Size, cm }\end{array}$ & Section & $\begin{array}{c}\text { O/A } \\
\text { Flow } \\
\text { Ratio }\end{array}$ & $\begin{array}{c}\text { Max Flow } \\
\text { Rate, } \\
\mathbf{m L / m i n}\end{array}$ & $\begin{array}{c}\text { Mode of } \\
\text { Failure }\end{array}$ & $\begin{array}{c}\text { Actual } \\
\text { Upper-Weir } \\
\text { Radius, mm }\end{array}$ & $\begin{array}{c}\text { Apparent } \\
\text { Upper-Weir } \\
\text { Radius, mm }\end{array}$ & $\begin{array}{c}\Delta \mathbf{r} / \mathbf{r}, \\
\mathbf{\%}^{\mathbf{a}}\end{array}$ & Notes \\
\hline 2 & Extr & 1.0 & 83 & A in O & 6.12 & 6.05 & -1.1 & $\mathrm{~b}$ \\
\hline & Extr & 0.2 & 61 & A in O & 6.12 & 6.01 & -1.8 & $\mathrm{~b}$ \\
\hline & Extr & 0.2 & 90 & A in O & 6.24 & 6.10 & -2.2 & c \\
\hline & Strip & 5.0 & 53 & A in O & 6.12 & 5.85 & -4.4 & $\mathrm{~b}$ \\
\hline 4 & Extr & 0.33 & 184 & A in O & 8.80 & 8.30 & -5.7 & $\mathrm{~d}$ \\
\hline & Extr & 1.0 & 302 & A in O & 8.80 & 8.50 & -3.4 & $\mathrm{~d}$ \\
\hline 5 & Extr & 0.33 & 2460 & A in O & 12.07 & 12.76 & 5.7 & $\mathrm{e}$ \\
\hline & Strip & 5.0 & 2900 & None & 12.07 & 12.35 & 2.3 & $\mathrm{e}$ \\
\hline
\end{tabular}

${ }^{\mathrm{a}} \Delta \mathrm{r} / \mathrm{r}=[$ (apparent upper-weir radius) - (actual upper-weir radius) $]$ / (actual upper-weir radius).

${ }^{\mathrm{b}}$ Rotor X1.

${ }^{c}$ Rotor X1 after upper weir has been opened up by EDM.

${ }^{\mathrm{d}}$ Same 4-cm ANL rotor used for both tests.

${ }^{\mathrm{e}}$ Same 5-cm CINC rotor with 0.950-in. (24.1-mm) upper-weir diameter used for both tests.

Results from earlier two-phase flow tests for the 2- and 4-cm contactor (see [R. LEONARD-2001B] and [ARAFAT-2002], respectively), are compared with the 5-cm CINC contactor results in Table 4. As with the one-phase flow tests for the 2- and 4-cm contactors, the two-phase flow tests show that the apparent radius for the upper weir is less than the actual radius. The amount of this change, -1.1 to $-4.4 \%$ for the $2-\mathrm{cm}$ contactor and -3.4 to $-5.7 \%$ for the 4-cm contactor, is in the same range as that for the one-phase flow tests.

In summary, the apparent radius for the upper weir in one-phase flow tests can be used to predict behavior in two-phase flow tests. Thus, the one-phase flow test is a quality control tool for evaluating contactor rotors as they are manufactured. These results indicate that the 5-cm CINC contactor works in the same way as the $2-$ and $4-\mathrm{cm}$ contactors and that the same model can be used in both cases. Some reasons why the apparent upper-weir radius might be greater than the actual radius for the 5-cm contactor while it is less for the 2- and 4-cm contactor rotors are given in the discussion section.

\section{Liquid Height in Mixing Zone}

Some liquid height in the annular mixing zone is required for high stage efficiency. The liquid volume provides a residence time for the two-phase dispersion in the mixing zone that, along with the high degree of mixing intensity provided by the spinning rotor and the continuous flow of each liquid phase to the stage, gives stage efficiencies that are typically greater than $95 \%$. 
It has been suggested that the annular liquid height may have been lower when curved bottom vanes were used below the rotor in place of straight bottom vanes, and so caused the lower stage efficiency observed [BIRDWELL-2001A].

In these tests, we measured the height of the annular liquid in the 5-cm CINC contactor for four straight vanes, eight straight vanes, and eight curved vanes. The experimental results are compared with the values predicted by an unpublished correlation that includes rotor diameter, annular gap, number of bottom vanes, liquid density, rotor speed, and flow rate [R. LEONARD-1982]. The liquid height as water flows through the mixing zone can be seen in Figures 7, 8, and 9 for four straight vanes, eight straight vanes, and eight curved vanes, respectively. The liquid height as the CSSX liquids flow through the mixing zone at an O/A of 0.33 for the extraction-section liquids and 5.0 for the strip-section liquids can be seen in Figure 10 for eight straight vanes. In all cases, for flow rates up to about $1000 \mathrm{~mL} / \mathrm{min}$, the actual liquid heights are at or above the correlation value. At low flow rates (between 80 and $300 \mathrm{~mL} / \mathrm{min}$ ) with eight vanes (either straight or curved), the liquid height seems to level out to a value between 8 and $10 \mathrm{~mm}$. For the four straight vanes, the liquid level is somewhat higher. At high flow rates (above 700 to $1200 \mathrm{~mL} / \mathrm{min}$ ) for all vane systems, the liquid height drops below that given by the correlation and becomes almost independent of the flow rate. To ensure that the liquid in the annular mixing zone does not bypass the centrifugal separating zone inside the rotor and go directly to the lower collector ring, the liquid height in the annulus is kept to $67 \%$ or less of the total annular height. Since the total annular height is $92 \mathrm{~mm}$ in the 5 -cm CINC contactor, the liquid height should be less than $61 \mathrm{~mm}$. Thus, while the four-vane system was tested, it is not recommended because the liquid heights are close to borderline. The eight-vane systems are recommended because the liquid height stays below $50 \mathrm{~mm}$ up to flow rates of $2400 \mathrm{~mL} / \mathrm{min}$. Note that the curved vanes give as much or more liquid height than the straight vanes. 


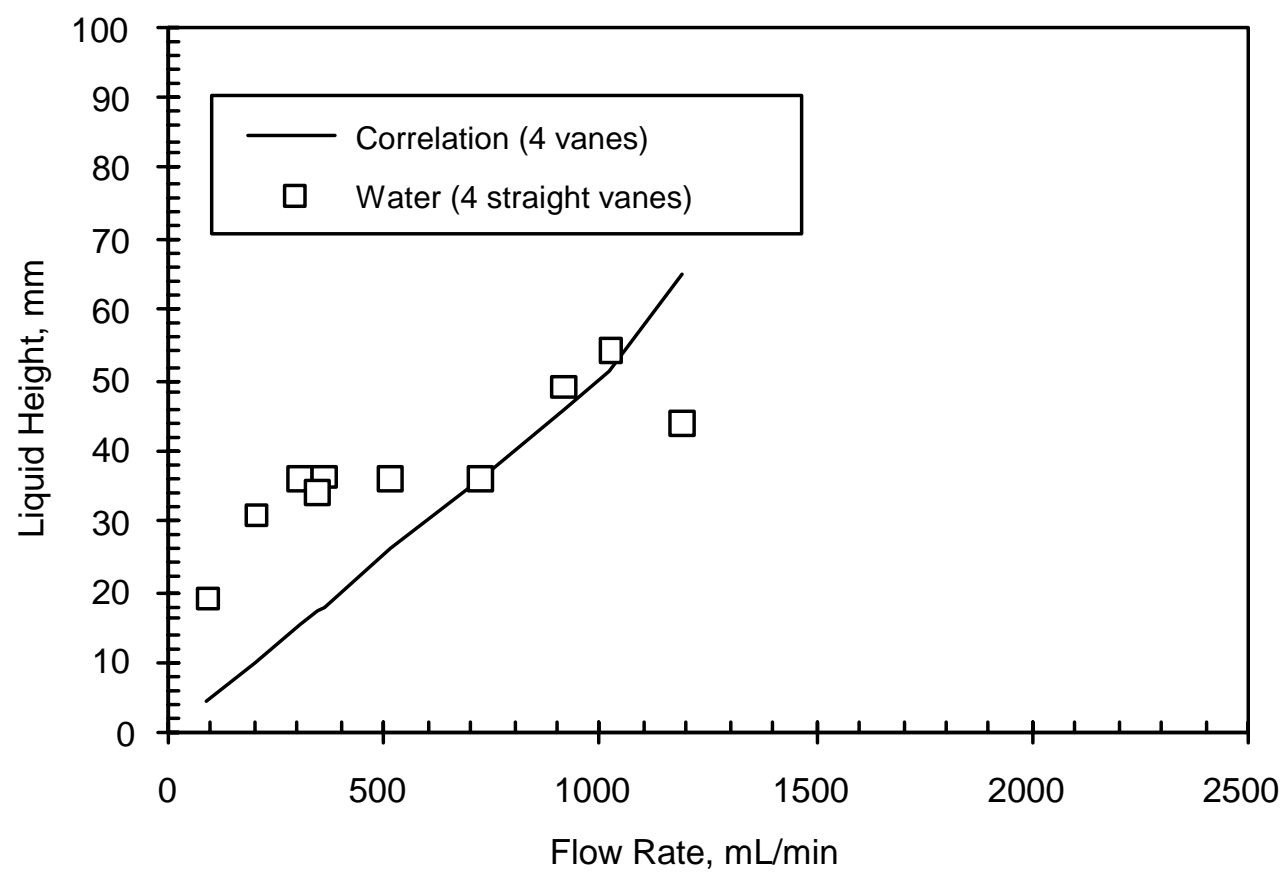

Fig. 7. Annular Liquid Height in 5-cm CINC Contactor Using Four Straight Bottom Vanes and Water

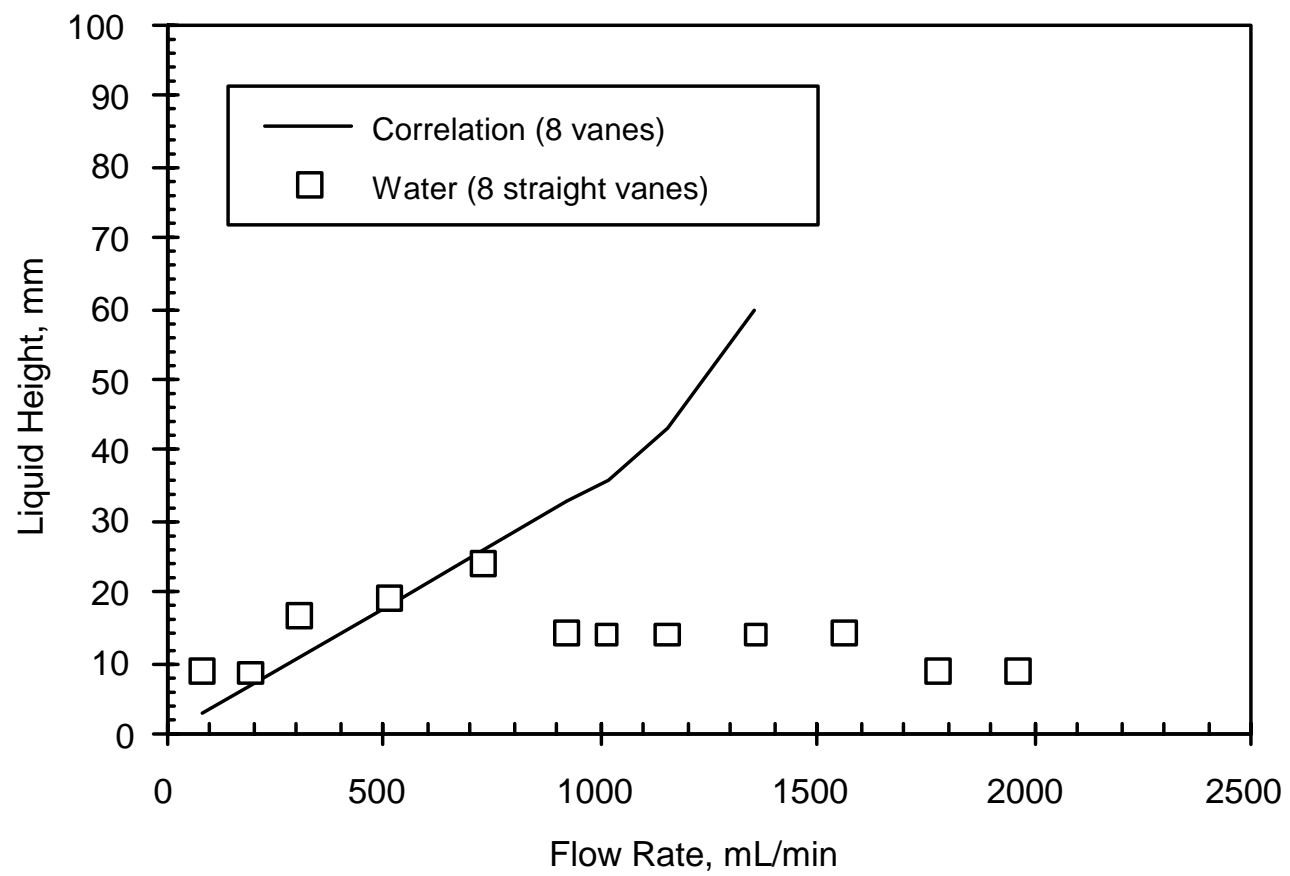

Fig. 8. Annular Liquid Height in 5-cm CINC Contactor Using Eight Straight Bottom Vanes and Water 


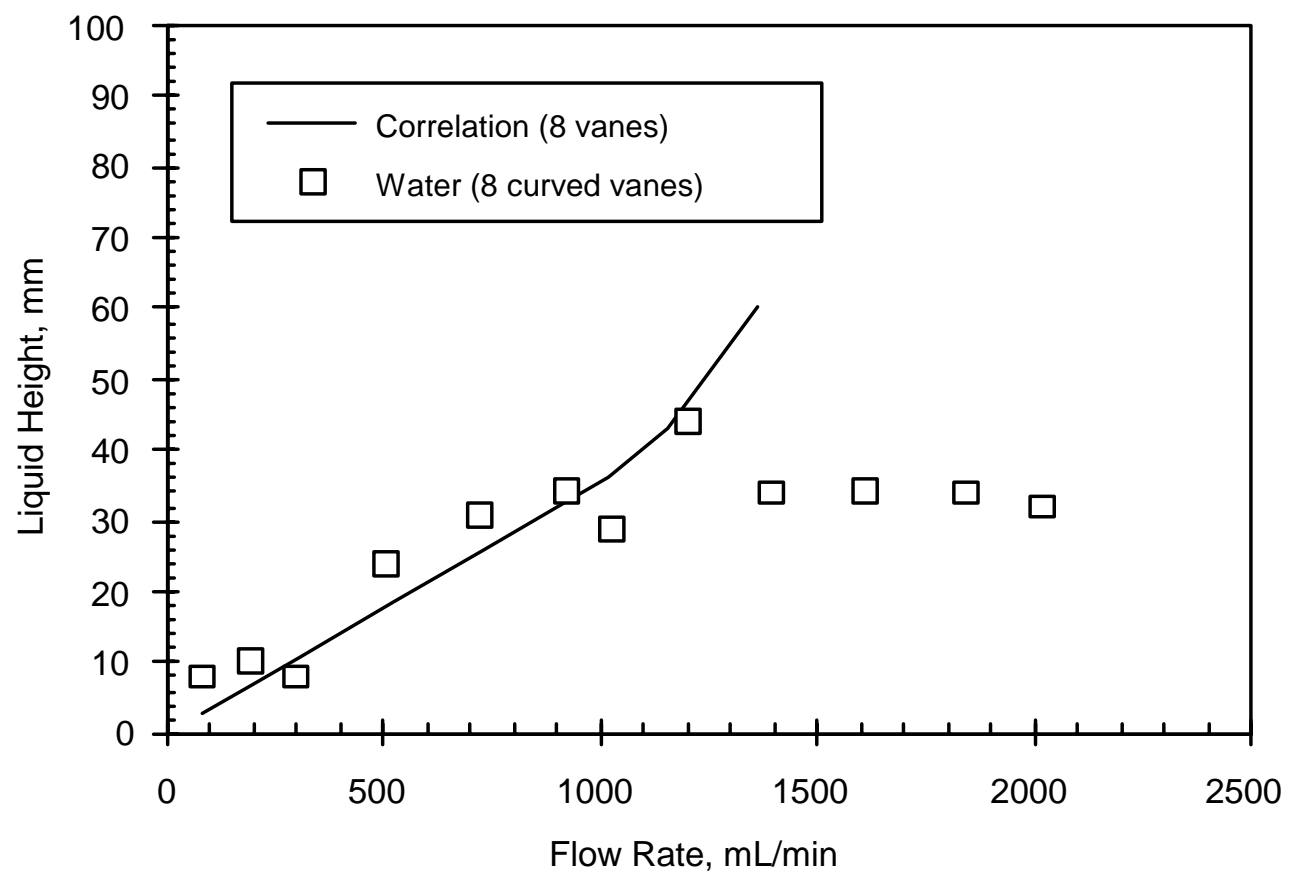

Fig. 9. Annular Liquid Height in 5-cm CINC Contactor Using Eight Curved Bottom Vanes and Water

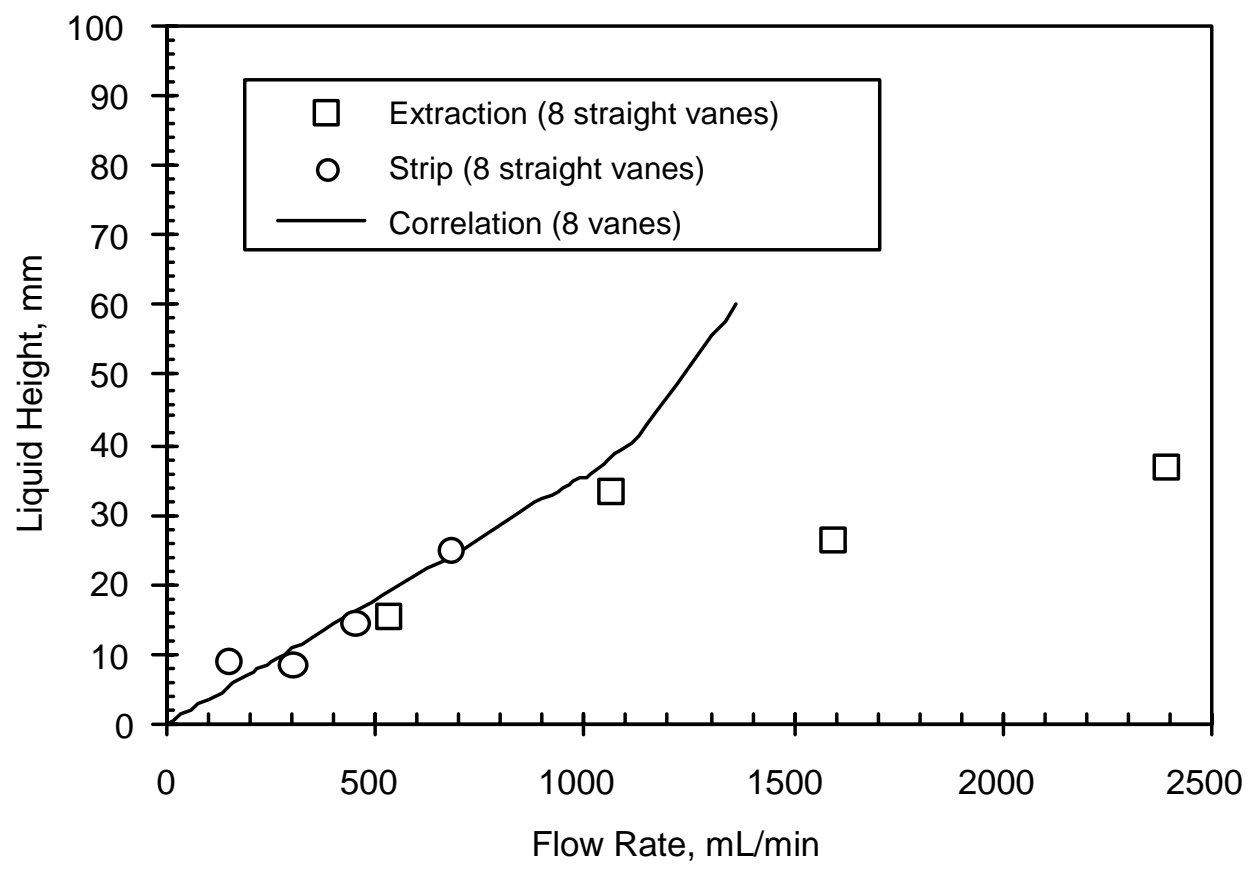

Fig. 10. Annular Liquid Height in 5-cm CINC Contactor Using Eight Straight Bottom Vanes and CSSX Conditions 


\section{Slug Flow}

Typically, the momentum imparted to the liquid as it is spun out of the rotor and is captured in the collector ring carries it on out of the collector ring into the exit port. The outlet port from the collector ring is tangential to the ring, so the liquid momentum is not lost and there is a smooth continuous flow of liquid from stage to stage. A continuous flow is required if high single-stage efficiency is going to lead to high multistage efficiency. However, at low flow rates, the liquid loses its momentum in the collector ring. The liquid level in the collector ring then rises until gravity forces overcome surface tension forces and a slug of liquid flows out of the collector ring into the exit port. When this discontinuous liquid flow is seen in the interstage lines, it is called "slug flow" and reduces the apparent efficiency during multistage operations. It has been observed in the operation of the $2-\mathrm{cm}$ contactor that slug flow occurs below $100 \mathrm{~mL} / \mathrm{min}$ [R. LEONARD-1999]. Most of these observations were below $40 \mathrm{~mL} / \mathrm{min}$. In the one-stage 5-cm CINC tests, we determined the flow rate at which slug flow occurs in the effluent lines. We focused on flow rates from 25 to $100 \mathrm{~mL} / \mathrm{min}$ since this would be the flow-rate range for the aqueous strip in a $1 / 100$ scale pilot plant for the CSSX process. The results, given in Table 5, show that slug flow was not observed above $50 \mathrm{~mL} / \mathrm{min}$. (Note that slug-flow results are given for the flow rate in the interstage or effluent line; they are not the total flow rate for both phases.) At flow rates from 25 to $50 \mathrm{~mL} / \mathrm{min}$, slug volumes are $2.7 \pm 1.0 \mathrm{~mL}$. 
Table 5. Slug Volume as Flowing Water Exits from 5-cm CINC Contactor

\begin{tabular}{|c|c|c|c|c|c|}
\hline $\begin{array}{c}\text { Flow } \\
\text { Rate, } \\
\mathbf{m L} / \mathbf{m i n}\end{array}$ & $\begin{array}{c}\text { Number of } \\
\text { Slugs }\end{array}$ & $\begin{array}{c}\text { Total } \\
\text { Collection } \\
\text { Time, } \mathbf{s}\end{array}$ & $\begin{array}{c}\text { Total Slug } \\
\text { Volume, mL }\end{array}$ & $\begin{array}{c}\text { Slug } \\
\text { Volume, } \\
\text { mL }\end{array}$ & $\begin{array}{c}\text { Annular } \\
\text { Liquid } \\
\text { Height } \\
\text { mm }\end{array}$ \\
\hline 0 & - & - & - & - & 5 \\
\hline 25 & 12 & 60 & 23 & 1.9 & $34^{\mathrm{b}}$ \\
\hline 30 & 17 & 60 & 29.5 & 2.5 & $35^{\mathrm{b}}$ \\
\hline 40 & 14 & 60 & 42 & 3.0 & $13^{\mathrm{b}}$ \\
\hline 50 & 30 & 60 & 50 & 1.7 & $\mathrm{NM}^{\mathrm{c}}$ \\
\hline 50 & 10 & 37 & 37 & 3.7 & $17^{\mathrm{b}}$ \\
\hline 60 & None $^{\mathrm{d}}$ & - & - & - & 6 \\
\hline 70 & None $^{\mathrm{d}}$ & - & - & - & $35^{\mathrm{b}}$ \\
\hline 80 & None $^{\mathrm{d}}$ & - & - & - & $14^{\mathrm{b}}$ \\
\hline
\end{tabular}

${ }^{\mathrm{a}}$ Measured from the bottom edge of the rotor to the upper point of contact with the rotor except as noted.

${ }^{b}$ Measured from the bottom edge of the rotor to the upper edge of liquid at the outer wall of the mixing zone.

${ }^{\mathrm{c}}$ Not measured.

${ }^{\mathrm{d}}$ Smooth continuous flow.

To evaluate these observations, we examined the effect of slug volume on mass transfer efficiency during multistage operation of the 2-cm contactor [R. LEONARD-2001C]. For an unmodified $2-\mathrm{cm}$ contactor, the slug volume was $100 \%$ of the liquid volume in the mixing zone, about $2 \mathrm{~mL}$. After the 2 -cm contactor rotor was modified so that the annular liquid volume was increased to about $4 \mathrm{~mL}$, the slug volume was only $50 \%$ of liquid volume in the mixing zone. After a second change, the wire rope in the interstage line, the slug volume out of the interstage line was reduced to about $0.16 \mathrm{~mL}$. These two changes reduced the slug volume to only $4 \%$ of the annular liquid volume and increased the efficiency for multistage operation from $60 \%$ to 90\%. By comparison, for the 5-cm CINC contactor, the annular liquid height for flow rates between 25 and $80 \mathrm{~mL} / \mathrm{min}$ (both phases) can be as low as $6 \mathrm{~mm}$ (see Table 5). For this height, the volume of liquid in the mixing zone [2-in.- (50.8-mm-) diameter rotor with 0.25 -in.- (6.4-mm-) annular gap] is $27.4 \mathrm{~mL}$. Since the average slug volume is $2.7 \mathrm{~mL}$, the slug volume is only $10 \%$ of the annular liquid volume. Based on our experience with the 2-cm contactor, at this slug volume relative to the annular liquid volume, the efficiency for multistage operation should be increased to about $85 \%$. At smaller slug volumes or higher annular liquid 
heights, the efficiency for multistage operation should reach or exceed $90 \%$. Thus, there should be minimal degradation of multistage mass-transfer efficiency in a contactor bank designed for a CSSX flowsheet being tested at 1/100-scale throughputs. (The waste-feed flow rate for the plantscale process is $20.1 \mathrm{gpm}$ [76.1 L/min].) Higher throughputs in larger contactor banks will result in even less degradation of the multistage efficiency.

While examining slug flow behavior for water in the 5-cm CINC contactor with the eight straight vanes, we noticed a second cause of slug flow. In the range from 30 to $70 \mathrm{~mL} / \mathrm{min}$, the liquid in the annular mixing zone would occasionally lose contact with the rotor. When this happened, the entering liquid would flow smoothly down the outer wall of the mixing zone into the pool of liquid under the rotor. They would not mix until the level of the liquid in the pool rose to the bottom surface of the rotor. At the moment of contact, some liquid was immediately sucked into the rotor without being significantly mixed. Because of the appearance when the liquid touches the rotor, this intermittent action is referred to as "flushing behavior". It generates a second type of slug, which is not reported in Table 5. Since the volume for this type of slug is on the same order of magnitude as the volume under the rotor (about $80 \mathrm{~mL}$ ) it can be as much as $300 \%$ of the volume in the annular mixing zone. Again, based on our experience with $2-\mathrm{cm}$ contactors, this type of slug could reduce the stage efficiency to less than $60 \%$. Consequently, we recommend that the $5-\mathrm{cm}$ CINC contactor not be operated below $80 \mathrm{~mL} / \mathrm{min}$ (both phases). The range of flow rates being considered for a CSSX flowsheet being tested at 1/100-scale throughputs would all be higher than $80 \mathrm{~mL} / \mathrm{min}$ (both phases).

\section{DISCUSSION}

The model for centrifugal contactor operation fits the experimental data well. The relation of the apparent radius to the actual radius is about the same for one- and two-phase flows. Using the one-phase flow test to measure the zero-point flow rate, it is easy to compare an existing rotor with the model. This test can be a quality assurance check of each rotor after construction. It provides a good measurement of overall rotor operation.

While the model works well for the three rotor sizes tested, there were differences between various rotor sizes. For the 2- and 4-cm contactors designed and built at ANL, the apparent radius of the upper weir was less than the actual radius. For the 5-cm contactor designed and built at CINC, the apparent radius of the upper weir was greater than the actual radius. These differences reflect the limitations of the model and show why the value for the upper-weir radius of a newly designed rotor should always be evaluated by hydraulic testing. 
Two differences in the ANL and CINC designs can account for the observed differences in the apparent radius for the upper weir. First, the tubes or slots (called the "underflow") from the separating zone to the riser region before the upper weir are very short in the CINC design and quite long for the ANL design. The ANL design for the underflow uses long tubes or slots so that the riser is narrow and creates a high liquid velocity up to the upper weir, which carries out any fine suspended solids that might be brought into the contactor by the feed solutions. The narrow riser creates a strong Coriolis effect that makes the liquid level over the upper weir higher [DAVIS-1961]. The wider riser of the CINC design creates a smaller Coriolis effect, making the liquid level over the upper weir less and, hence, the apparent radius larger.

The second difference between the two designs results from four vanes behind (downstream of) the upper weir. In the ANL design, these vanes are an integral part of the weir plate. In the CINC design, these vanes are attached to the other (lower) wall of the riser and extend vertically upward to meet the upper-weir plate. An annular ring of metal presses against the upper-weir plate and keeps it next to the vanes. The ring clamps on the outer edge of the weir plate, not near the weir itself, possibly forcing the weir slightly upward. That would create a small gap between the vanes and the weir at the point where the liquid flows over the weir. Such a gap would allow some liquid to flow between the vane quadrants, which would also lower the level of the liquid over the weir and make the apparent radius of the upper weir larger. Thus, subtle differences between the design of the ANL and CINC rotors can explain why the apparent radius for the upper weir is different. Once the relationship between the actual and apparent upper radius is known, the actual radius can be machined appropriately based on model calculations.

Slug flow in the 5-cm CINC contactor seems to disappear at flow rates as low as those in the 2-cm contactor. This may be the result of the clamp plate over the upper weir of the CINC unit. This plate has slots in it to allow the liquid flowing over the upper weir to reach the upper collector ring. The exiting liquid passes the outer edge of the slots, increasing the momentum. In contrast, the upper (downstream) face of the upper weir in the 2- and 4-cm contactor is completely smooth. Thus, the liquid exiting the upper weir of the 5-cm CINC unit will have more momentum from the clamp plate. The exiting liquid will get an additional momentum boost, since the radius of the 5-cm CINC unit is larger than the 2- and 4-cm ANL units while all three rotors are operating at the same speed.

The correlation of liquid height in the annular mixing zone is seen to be useful, but should be used with caution. At very low flow rates, it may give values that are too low. At very high flow rates, the liquid level stops rising as predicted by the correlation. The model needs to 
be revised so that it predicts when the liquid level will stop rising. Without this information, rotor designs will be more conservative than they need to be.

In the measurement of liquid height in the annular mixing zone, several factors have to be considered. Typically, the annular liquid height is greater at the outer housing wall than at the rotor wall. Except for some water-only flow tests, which are noted, we measured the height at the outer wall. For two-phase flow, this is the only height that can be seen. This outer-wall height is the value that would be obtained if a manometer were attached tangentially to the mixing zone wall so that fluid momentum in the mixing zone was excluded. Sometimes, the annular liquid height moves up and down. In these cases, we took the lowest point as the liquid height in the annular mixing zone. If the incoming liquid interacts with the spinning annular liquid, the height is read at a point on the circumference where the interaction is at a minimum.

The inlet ports on the 5-cm acrylic (clear) CINC housing are tangential to the wall of the mixing zone. Those on the 5-cm stainless steel CINC housing, as well as those on the 2- and 4-cm contactors, are perpendicular. The tangential design is preferred, but in most cases, contactor operation will not be affected, especially if the inlet port is being fed by a pump. However, if the flow is coming from an adjacent stage via an interstage line and the liquid level in the mixing zone rises until it reaches the inlet ports, the interaction of the spinning liquid with the perpendicular inlet ports can put some pressure on the incoming liquid and cause it to back up into the interstage line. This can lead to flooding of the contactor at flow rates that would otherwise be acceptable. With the tangential inlet ports, the only pressure on the incoming liquid will be from the level of the liquid, if any, above these ports. The spinning mixing-zone liquid will help to draw the interstage liquid into the annular region.

Another concern for the proper operation of the inlet ports is the entry of the other phase into a port. This is especially important when the liquid height in the annular mixing zone is at or above the inlet ports. One solution is to have the line for the less-dense-phase inlet come down from above and the line for the more-dense-phase inlet come up from below. Thus, when the other phase enters the inlet tube, it has no place to go. Sometimes this solution is not available. For example, the interstage lines always come down to the inlet port. In this case, while the more-dense phase has nowhere to go, the less-dense phase can rise up as high as the liquid in the annular mixing zone. However, if the inlets have a tangential orientation, the lessdense phase will rise no higher, which is not a problem. The entering more-dense phase will sink below the less-dense phase and continue on into the mixing zone. When the inlet port is an external feed port, the line from the feed pump to the port can be placed so that the less-dense phase comes down from above and the more-dense phase comes up from below. An alternative 
solution is to make the feed line enough smaller that the liquid velocity in the feed line prevents the other phase from entering.

In working with the acrylic housing for the 5-cm CINC contactor, we found that the solvent softens the housing and makes it cloudy, especially when the aqueous phase is highly alkaline. To limit this damage, we minimized the testing duration. After testing, the unit was immediately drained and flushed with water.

The 5-cm CINC contactor has two sets of bearings, one in the drive motor and the other, for the rotor, just above the clamp plate that holds the upper-weir plate in place. A flexible coupling transmits the torque from the motor down to the rotor. The rotor bearings for our unit were stiff. As a result, the housing holding the rotor bearings heated up, while the motor itself was cool to the touch. With the motor running alone, the electrical current to the motor was $0.2 \mathrm{~A}$. With the rotor attached to the motor, the electrical current was initially $0.4 \mathrm{~A}$. After $5 \mathrm{~min}$, it dropped to $0.3 \mathrm{~A}$. This level of electrical current for the drive motor is considered typical for 5-cm CINC contactors [D. LEONARD-2001].

In designing contactors, we do not have a specification for the total indicating runout (TIR) at the bottom of the rotor. The TIR tells us the combined effect from (1) the rotor body being out of round, (2) the rotor body not being quite concentric with the rotor shaft, (3) the rotor shaft not being quite concentric with the motor shaft, (4) the motor shaft not being quite concentric with the motor bearings, and (5) the motor shaft being bent. For the 2-cm contactor, we found that contactor operation was good up for TIR values to 10 mils $(0.254 \mathrm{~mm})$. At a TIR of less than 5 mils $(0.127 \mathrm{~mm})$, rotor wobble was no longer visually detectable. For the 4-cm contactor, TIR varied from 5 to 11 mils $(0.127$ to $0.279 \mathrm{~mm})$. For the $5-\mathrm{cm}$ CINC contactor, the TIR was $4.5 \pm 0.5$ mils $(0.114 \pm 0.013 \mathrm{~mm})$. With the 2 -cm contactor, we might be able to return to a maximum allowable TIR of 12 mils $(0.305 \mathrm{~mm})$ if we use tangential inlet ports. For larger contactor rotors, some increase in the maximum allowable TIR may be possible. This area will need careful attention as we build larger contactors.

For a pilot plant that is $1 / 100$ of the full-scale plant with a waste feed rate of $20.1 \mathrm{gpm}$ $(76.1 \mathrm{~L} / \mathrm{min})$, a solvent feed rate of $6.6 \mathrm{gpm}(25.0 \mathrm{~L} / \mathrm{min})$, and an O/A flow ratio of 5.0 in the scrub section, the total flow rate (both phases) in the extraction section would be $1061 \mathrm{~mL} / \mathrm{min}$. A maximum flow rate that is $50 \%$ higher would be $1591 \mathrm{~mL} / \mathrm{min}$. Having an upper limit that is $50 \%$ higher so the multistage perturbations can be accommodated, a flow rate of $2390 \mathrm{~mL} / \mathrm{min}$ would be needed. As can be seen from Table 4, the 5-cm CINC contactor can just meet this specification. We do not know if it will have the required stage efficiency of $80 \%$ or greater. 
High stage efficiencies have been measured in the 5-cm CINC contactor, but they were for much lower flow rates, up to $634 \mathrm{~mL} / \mathrm{min}$ [BIRDWELL-2001A, -2001B]. Based on the hydraulic performance tests done here, the model predicts that stage efficiency for the extraction section should be $>97 \%$ for flow rates up to $2390 \mathrm{~mL} / \mathrm{min}$. Of course, this needs to be tested experimentally before the 5-cm CINC contactor is used for a 1/100-scale pilot plant.

For the same 1/100-scale pilot plant, the strip section flow rates are much lower. The baseline flow rate for the aqueous strip feed is $50 \mathrm{~mL} / \mathrm{min}$ and can vary from 25 to $75 \mathrm{~mL} / \mathrm{min}$ with an upper limit of $113 \mathrm{~mL} / \mathrm{min}$. The solvent flow rate is $250 \mathrm{~mL} / \mathrm{min}$ and can vary from 125 to $375 \mathrm{~mL} / \mathrm{min}$ with an upper limit of $562 \mathrm{~mL} / \mathrm{min}$. Based on the hydraulic performance tests done here, the stage efficiency should be high for the strip section as well. Again, this needs to be tested before the 5-cm CINC contactor is used for a 1/100-scale pilot plant.

No model exists for predicting when flushing will occur. It has been seen only when the flow rate and, hence, the liquid level in the annular mixing zone, is low. When it occurs, it can cause slugs with large volumes that could degrade stage efficiencies below $60 \%$. For the $5-\mathrm{cm}$ CINC contactor, flushing is not a concern, as it occurs at flow rates below what we need for the 1/100-scale CSSX pilot plant. In general, before a contactor is selected for a solvent extraction process, it should be tested for flushing over the range of expected operation.

Because the curved vanes are shaped so as to lead the spinning liquid inwards toward the rotor inlet, we thought that liquid height in the annular mixing zone would be lower for the eight curved vanes than for the eight straight vanes. However, this was not the case. In fact, for water flowing alone through the mixing zone, the liquid height was greater for the curved vanes, especially at high flows (see Figs. 8 and 9). When the straight vanes were used for two-phase flows, the liquid heights were very close to those for the curved vanes (see Figs. 9 and 10). We observed more agitation in the annular mixing zone when curved vanes were used. In the work at ORNL, the contactor housing was switched from curved vanes to straight vanes to get higher liquid height and consequent higher stage efficiency [BIRDWELL-2001A]. As the housing was stainless steel, the actual liquid height could not be seen. Although higher stage efficiency was obtained, something other than the curved vanes may have caused the low stage efficiency. Based on the tests reported here, the hydraulic differences between straight and curved vanes seem minimal. We recommend the straight vanes because they are easier to fabricate.

The model for two-phase operation assumes that the dispersion number is constant. As noted above, the dispersion number can range from $4 \times 10^{-4}$ to $12 \times 10^{-4}$ depending on how it was measured. Thus, any model based on it should be treated as only a guide for contactor design 
and operation. The dispersion number (phase disengagement break times in [MOYER-2001]) does show that there is very little difference between the full SRS simulant and a salts-only simulant. Thus, the four-component simulant used here should be a reasonable substitute for the full SRS simulant. The dispersion number can also show when the continuous phase is important by looking at both high and low O/A volume ratios [R. LEONARD-1995, -1999].

As noted in the experimental section, the solvent density increased with use, which suggests some loss of the most volatile solvent component, the Isopar ${ }^{\circledR} \mathrm{L}$. Thus, we will be monitoring solvent density more closely in the future. A high solvent density could also explain the results for the 0.950-in. (24.1-mm) upper weir under stripping conditions reported by Birdwell, including the fact that the failure mode was $\mathrm{O}$ in $\mathrm{A}$ at a total flow rate of $750 \pm 30 \mathrm{~mL} / \mathrm{min}$ [BIRDWELL-2001A]. Using the model, we find that such operation would be consistent with a solvent density of $875 \pm 10 \mathrm{~g} / \mathrm{L}$. More recently, Birdwell has reported that this solvent, which initially had a density of $822.7 \pm 0.2 \mathrm{~g} / \mathrm{L}$ at $25^{\circ} \mathrm{C}$ [MOYER-2001], now has a density of $925.6 \mathrm{~g} / \mathrm{L}$ at $25^{\circ} \mathrm{C}$ [BIRDWELL-2001B]. The calculated density for the earlier Birdwell tests [BIRDWELL-2001A] is in general agreement with the overall change in measured solvent density.

A 5-cm CINC rotor was made partially pumping by opening the rotor inlet so that it could pump the liquid from the bottom of the rotor only part way to the top [BIRDWELL-2001A]. To get the rest of the way to the top, the liquid in the annular mixing zone must rise by the same amount. This rotor modification was done to improve stage efficiency and is reported to have succeeded. However, the work done here with both curved and straight vanes shows that there is enough liquid in the annular mixing zone to get stage efficiencies of $97 \%$ or greater in singlestage contactor tests, which suggests that there might not have been a need to make the rotor partially pumping. The $2-\mathrm{cm}$ contactors at ANL were also made partially pumping to improve their stage efficiency [R. LEONARD-2001C]. In that case, we measured single-stage efficiency and found it was high. By increasing the volume in the annular mixing zone, we hoped to reduce the effect of slugs in the interstage line on the stage efficiency for multistage operation. However, because another change was made at the same time (the use of the wire rope in the interstage lines), we are not sure how important it was to make the rotor partially pumping. Because the wire rope had a big effect on slug volume, it was probably more important. After the 5-cm CINC contactor work was completed here, we learned that further ORNL work on a single-stage 5-cm CINC contactor showed no difference in stage efficiency between partially and fully pumping rotors when straight bottom vanes are used in both cases [BIRDWELL-2001B]. If a partially pumping rotor is desired, its use should be reviewed with care to be sure that nothing else is adversely affected. In general, we recommend that rotors be designed to be fully pumping. 


\section{ACKNOWLEDGMENTS}

This work was supported by the U.S. Department of Energy, Office of Environmental Management, through (1) the Office of Project Completion and (2) the Tank Focus Area of the Office of Science and Technology under Contract W-31-109-Eng-38 with Argonne National Laboratory, managed by the University of Chicago.

\section{REFERENCES}

ARAFAT-2002

H. A. Arafat, J. R. Falkenberg, and R. A. Leonard, Solvent Recovery from Aqueous Effluent using Process Diluent in the Caustic-Side Solvent Extraction (CSSX) Process, Argonne National Laboratory Report, ANL-02/31, in preparation (2002).

BERNSTEIN-1973

G. J. Bernstein, D. E. Grosvenor, J. F. Lenc, and N. M. Levitz, "A High-Capacity Annular Centrifugal Contactor,” Nucl. Technol. 20, 200-202 (1973).

\section{BIRDWELL-2001A}

J. F. Birdwell, Jr., and K. K. Anderson, Evaluation of 5-cm Centrifugal Contactor Hydraulic and Mass Transfer Performance for Caustic-Side Solvent Extraction of Cesium, Oak Ridge National Laboratory Report ORNL/TM-2001/137 (2001).

\section{BIRDWELL-2001B}

J. F. Birdwell, Jr., and K. K. Anderson, Evaluation of Mass Transfer Performance for Caustic-Side Solvent Extraction of Cesium in a Conventional 5-cm Centrifugal Contactor, Oak Ridge National Laboratory Report ORNL/TM-2001/278 (January 2002).

BONNESEN-2000

P. V. Bonnesen, L. H. Delmau, B. A. Moyer, and R. A. Leonard, "A Robust AlkalineSide CSEX Solvent Suitable for Removing Cesium from Savannah River High-Level Waste," Solv. Extr. Ion Exch. 18(6), 1079-1108 (2000).

CAMPBELL-2001

S. G. Campbell, M. W. Geeting, C. W. Kennell, J. D. Law, R. A. Leonard, M. A. Norato, R. A. Pierce, T. A. Todd, D. D. Walker, and W. R. Wilmarth, Demonstration of CausticSide Solvent Extraction with Savannah River Site High Level Waste, Westinghouse Savannah River Company Technical Report WSRC-TR-2001-00223 (April 2001). 


\section{DAVIS-1961}

M. W. Davis, Jr., and A. S. Jennings, "Equipment for Processing by Solvent Extraction," in Chemical Processing of Reactor Fuels, J. F. Flagg, editor, Academic Press, New York, 271-303 (1961).

LEONARD, D.-2001

D. Leonard, CINC, private communication, December 2001.

LEONARD, R.-1981

R. A. Leonard, G. J. Bernstein, R. H. Pelto, and A. A. Ziegler, "Liquid-Liquid Dispersion in Turbulent Couette Flow," AIChE Journal 27, 495-503 (1981).

LEONARD, R.-1982

R. A. Leonard, unpublished data and correlation, Argonne National Laboratory (1982).

LEONARD, R.-1983

R. A. Leonard, A. A. Ziegler, R. A. Wigeland, R. W. Bane, and M. J. Steindler, "Operation with Three Liquid Phases in a Staged Liquid-Liquid Contactor," Sep. Sci. Technol. 18, 1563-1579 (1983).

LEONARD, R.-1988

R. A. Leonard, "Recent Advances in Centrifugal Contactor Design," Sep. Sci. Technol. 23, 1473-1487 (1988).

LEONARD, R.-1993

R. A. Leonard, D. G. Wygmans, M. J. McElwee, M. O. Wasserman, and G. F. Vandegrift, "The Centrifugal Contactor as a Concentrator for Solvent Extraction Processes," Sep. Sci. Technol. 28(1-3), 177-200 (1993).

LEONARD, R.-1995

R. A. Leonard, "Solvent Characterization using the Dispersion Number," Sep. Sci. Technol. 30, 1103-1122 (1995).

LEONARD, R.-1997

R. A. Leonard, D. B. Chamberlain, and C. Conner, "Centrifugal Contactors for Laboratory-Scale Solvent Extraction Tests,” Sep. Sci. Technol. 32(1-4), 193-210 (1997).

LEONARD, R.-1999

R. A. Leonard, C. Conner, M. W. Liberatore, J. Sedlet, S. B. Aase, and G. F. Vandegrift, Evaluation of an Alkaline-Side Solvent Extraction Process for Cesium Removal from SRS Tank Waste Using Laboratory-Scale Centrifugal Contactors, Argonne National Laboratory Report ANL-99/14 (1999). 
LEONARD, R.-2000

R. A. Leonard, S. B. Aase, H. A. Arafat, C. Conner, J. R. Falkenberg, and G. F. Vandegrift, Proof-of-Concept Flowsheet Tests for Caustic-Side Solvent Extraction of Cesium from Tank Waste, Argonne National Laboratory Report ANL-00/30, Argonne, IL (November 2000).

LEONARD, R.-2001A

R. A. Leonard, S. B. Aase, H. A. Arafat, D. B. Chamberlain, C. Conner, M. C. Regalbuto, and G. F. Vandegrift, Interim Report on a Multi-Day Test of the Caustic-Side Solvent Extraction Flowsheet for Cesium Removal from a Simulated SRS Tank Waste, Argonne National Laboratory Report ANL-01/10 (2001).

LEONARD, R.-2001B

R. A. Leonard, S. B. Aase, H. A. Arafat, C. Conner, D. B. Chamberlain, J. R. Falkenberg, M. C. Regalbuto, and G. F. Vandegrift, Multi-day Test of the Caustic-Side Solvent Extraction Flowsheet for Cesium Removal from a Simulated SRS Tank Waste, Argonne National Laboratory Report ANL-02/11 (2002).

LEONARD, R.-2001C

R. A. Leonard, S. B. Aase, H. A. Arafat, C. Conner, J. R. Falkenberg, and G. F. Vandegrift, Development of an Improved 2-cm Centrifugal Contactor for Cesium Removal from High-Level Waste, Argonne National Laboratory Report ANL-01/23, (2001).

\section{LEVENSON-2000}

M. Levenson, G. R. Choppin, J. Bercaw, D. H. Busch, T. Fryberger, G. E. Keller, M. Kozak, A. P. Sattelberger, B. E. Scheetz, and M. J. Steindler, Alternatives for High-Level Waste Salt Processing at the Savannah River Site, National Research Council, National Academy Press, Washington, DC (2000).

\section{MOYER-2001}

B. A. Moyer, S. D. Alexandratos, P. V. Bonnesen, G. M. Brown, J. E. Caton, L. H. Delmau, C. R. Duchemin, T. J. Haverlock, T. G. Levitskaia, M. P. Maskarinec, F. V. Sloop, and C. L. Stine, Caustic-Side Solvent Extraction Chemical and Physical Properties: Progress in FY 2000 and FY 2001, Oak Ridge National Laboratory Technical Report CERS/SR/SX/019 (2001).

\section{PETERSON-2000}

R. A. Peterson, Preparation of Simulated Waste Solutions for Solvent Extraction Testing, Westinghouse Savannah River Company Report WSRC-RP-2000-361 (May 1, 2000). 


\section{U.S. DEPARTMENT OF ENERGY-2001}

U.S. Department of Energy, "Record of Decision: Savannah River Site Salt Processing Alternatives,” Federal Register, 66(201), pp. 52752-52756, October 17, 2001.

WALKER-1998

D. D. Walker and G. K. Georgeton, Viscosity and Density of Simulated Salt Solutions, Westinghouse Savannah River Company Report WSRC-RP-89-1088 (October 19, 1989).

WEBSTER-1969

D. S. Webster, A. S. Jennings, A. A. Kishbaugh, and H. K. Bethmann, "Performance of Centrifugal Mixer-Settler in the Reprocessing of Nuclear Fuel," in W. A. Rodger and D. E. Ferguson, Eds., Recent Advances in Reprocessing of Irradiated Fuel, Nuclear Engineering--Part XX, American Institute of Chemical Engineers, New York, Chem. Eng. Prog. Symp. Ser. No. 94, 65, 70-77 (1969). 
Distribution List for ANL-02/18

Internal (Printed and Electronic Copies):
S. B. Aase
M. L. Dietz
K. L. Nash
H. A. Arafat
E. Freiberg
M. C. Regalbuto (5)
A. J. Bakel
A. V. Guelis
M. J. Steindler
D. B. Chamberlain
J. E. Helt
G. F. Vandegrift
Y. I. Chang
R. A. Leonard (5)
V. A. Davis
D. Lewis (2)
S. K. Zussman

Internal (Electronic Copy Only):

TIS Files

D. L. Bowers

R. J. Finch

E. C. Gay

C. J. Mertz

C. Pereira

J. Sedlet

\section{External (Printed and Electronic Copies):}

Chemical Technology Division Review Committee Members:

H. U. Anderson, University of Missouri-Rolla, Rolla, MO

R. A. Greenkorn, Purdue University, West Lafayette, IN

C. L. Hussey, University of Mississippi, University, MS

M. V. Koch, University of Washington, Seattle, WA

V. P. Roan, Jr., University of Florida, Gainesville, FL

J. R. Selman, Illinois Institute of Technology, Chicago, IL

J. S. Tulenko, University of Florida, Gainesville, FL

J. F. Birdwell, Oak Ridge National Laboratory, Oak Ridge, TN

P. V. Bonnesen, Oak Ridge National Laboratory, Oak Ridge, TN

S. G. Campbell, Westinghouse Savannah River Company, Aiken, SC

J. T. Carter, Westinghouse Savannah River Company, Savannah River Technology Center, Aiken, SC

C. Conner, BWX Technologies, Inc., Lynchburg, VA

L. H. Delmau, Oak Ridge National Laboratory, Oak Ridge, TN

H. D. Harmon, Westinghouse Savannah River Company, Aiken, SC

R. T. Jubin, Oak Ridge National Laboratory, Oak Ridge, TN

J. D. Law, Idaho National Engineering and Environmental Laboratory, Research Center, Idaho Falls, ID

R. Leugemors, Pacific Northwest National Laboratory, Richland, WA 
G. J. Lumetta, Battelle, Pacific Northwest National Laboratory, Richland, WA

B. A. Moyer, Oak Ridge National Laboratory, Oak Ridge, TN

M. Norato, Westinghouse Savannah River Company, Aiken, SC

R. A. Pierce, Westinghouse Savannah River Company, Aiken, SC

P. C. Suggs, DOE-SR, Aiken, SC

M. C. Thompson, Westinghouse Savannah River Company, Savannah River Technology Center, Aiken, SC

T. A. Todd, Idaho National Engineering and Environmental Laboratory, Idaho Falls, ID

D. D. Walker, Westinghouse Savannah River Company, Aiken, SC

External (Printed Copy Only):

Tanks Focus Area Technical Team, c/o B. J. Williams, Pacific Northwest National Laboratory, Richland, WA

Tanks Focus Area Field Leader, c/o T. P. Pietrok, DOE Richland Operations Office, Richland, WA

Tanks Focus Area Headquarters Program Manager, c/o K. D. Gerdes, DOE-EM, Germantown, MD

External (Electronic Copy Only):

ANL-E-Library

ANL-W-Library

DOE-OSTI

W. D. Clark, DOE-SR, Aiken, SC

S. M. Dinehart, Los Alamos National Laboratory, Weapon Component Technology, Los Alamos, NM

R. E. Edwards, Westinghouse Savannah River Company, Aiken, SC

S. D. Fink, Westinghouse Savannah River Company, Savannah River Technology Center, Aiken, SC

L. N. Klatt, Oak Ridge National Laboratory, Oak Ridge, TN

D. E. Kurath, Battelle, Pacific Northwest National Laboratory, Richland, WA

K. T. Lang, USDOE, Washington, DC

J. W. McCullough, USDOE, Aiken, SC

C. P. McGinnis, Oak Ridge National Laboratory, Oak Ridge, TN

M. Miles, Oak Ridge National Laboratory, Oak Ridge, TN

A. L. Olson, Idaho National Engineering and Environmental Laboratory, Idaho Falls, ID

M. J. Palmer, Los Alamos National Laboratory, Weapon Component Technology, Los Alamos, NM

L. M. Papouchado, Westinghouse Savannah River Company, Savannah River Technology Center, Aiken, SC

R. A. Peterson, Bechtel-Washington Process Technology, Richland, WA

B. M. Rapko, Battelle, Pacific Northwest National Laboratory, Richland, WA

R. D. Rogers, University of Alabama, Department of Chemistry, Tuscaloosa, AL

K. J. Rueter, Bechtel-Washington Process Technology, Richland, WA 
P. Rutland, Bechtel-Washington Process Technology, Richland, WA

S. Schlahta, Battelle, Pacific Northwest National Laboratory, Richland, WA

J. L. Swanson, Richland, WA

W. L. Tamosaitis, Westinghouse Savannah River Company, Savannah River Technology Center, Aiken, SC

L. L. Tavlarides, Syracuse University, Dept. of Chemical Engineering, Syracuse, NY

D. W. Tedder, Georgia Institute of Technology, Atlanta, GA

V. Van Brunt, University of South Carolina, Department of Chemical Engineering, Columbia, SC

J. F. Walker, Oak Ridge National Laboratory, Oak Ridge, TN

J. S. Watson, Oak Ridge National Laboratory, Oak Ridge, TN

R. M. Wham, Oak Ridge National Laboratory, Oak Ridge, TN

V. Wheeler, Oak Ridge National Laboratory, Oak Ridge, TN

W. R. Wilmarth, Westinghouse Savannah River Company, Aiken, SC 
